\title{
Physiology and glomerular projections of olfactory receptor neurons on the antenna of female Heliothis virescens (Lepidoptera: Noctuidae) responsive to behaviorally relevant odors
}

\begin{abstract}
The neurophysiology and antennal lobe projections of olfactory receptor neurons housed within short trichoid sensilla of female Heliothis virescens F. (Noctuidae: Lepidoptera) were investigated using a combination of cut-sensillum recording and cobaltlysine staining techniques. Behaviorally relevant odorants, including intra- and inter-sexual pheromonal compounds, plant and floral volatiles were selected for testing sensillar responses. A total of 184 sensilla were categorized into 25 possible sensillar types based on odor responses and sensitivity. Sensilla exhibited both narrow (responding to few odors) and broad (responding to many odors) response spectra. Sixty-six percent of the sensilla identified were stimulated by conspecific odors; in particular, major components of the male $H$. virescens hairpencil pheromone (hexadecanyl acetate and octadecanyl acetate) and a minor component of the female sex pheromone, (Z)-9-tetradecenal. Following characterization of the responses, olfactory receptor neurons within individual sensilla were stained with cobalt lysine $(N=39)$ and traced to individual glomeruli in the antennal lobe. Olfactory receptor neurons with specific responses to (Z)-9-tetradecenal, a female $H$. virescens sex pheromone component, projected to the female-specific central large female glomerulus (cLFG) and other glomeruli. Terminal arborizations from sensillar types containing olfactory receptor neurons sensi-
\end{abstract}

Electronic Supplementary Material Supplementary material is available for this article at http://dx.doi.org/10.1007/s00359 005 $0061 \mathrm{x}$ and is accessible for authorized users.

N. K. Hillier $(\square) \cdot$ N. J. Vickers

Department of Biology, University of Utah,

Room 201 South Biology, Salt Lake City, UT 84112, USA

E mail: hillier@biology.utah.edu

Tel.: + 18015814795

Fax: +18015814668

C. Kleineidam

Department of Behavioral Physiology and Sociobiology,

Zoologie II, Biozentrum, Am Hubland,

97074, Würzburg Germany tive to male hairpencil components and plant volatiles were also localized to distinct glomerular locations. This information provides insight into the representation of behaviorally relevant odorants in the female moth olfactory system.

Keywords Olfaction - Cobalt-lysine staining · Sensillum $\cdot$ Antennal lobe $\cdot$ Receptor neuron

Abbreviations Z11-16:Ald: (Z)-11-hexadecenal • Z9-14:Ald: (Z)-9-tetradecenal - Z9-16:Ald: $(Z)-9-$ hexadecenal $\cdot$ Z11-16:OAc: $(Z)-11$-hexadecenyl acetate $\cdot$ Z11-16:OH: $(Z)-11$-hexadecen-1-ol $\cdot 14: \mathrm{OOH}$ : tetradecanoic acid $\cdot 16: \mathrm{OH}$ : hexadecanol $\cdot 18: \mathrm{OH}$ : octadecanol $\cdot$ 16:OAc: hexadecanyl acetate $\cdot 18$ :OAc: octadecanyl acetate $\cdot 16: \mathrm{OOH}$ : hexadecanoic acid - 18:OOH: octadecanoic acid - Z3-6:OH: $(Z)-3-$ hexen-1-ol - Z3-6:OAc: $(Z)$-3-hexenyl acetate E2-6:Ald: $(E)$-2-hexenal - ORN: olfactory receptor neuron - PN: projection neuron AL: antennal lobe - MGC: macroglomerular complex - LFG: large female glomeruli - cLFG: central large female glomerulus - mLFG: medial large female glomerulus $\cdot$ EAG: electroantennogram $\cdot$ SSR: single sensillum recording

\section{Introduction}

In male and female moths, odors play an important role in the location of potential mates, food sources and oviposition sites (Cardé 1984; Hartlieb et al. 1999; Kennedy 1977; Landolt and Phillips 1997; Visser 1986). In particular, the orientation of male moths to female produced sex pheromone is a well-described phenomenon (Cardé and Baker 1984; Kennedy and Marsh 1974; Kennedy et al. 1980; Kennedy et al. 1981; Murlis et al. 1992; Vickers and Baker 1992). The behavioral, sensory and central discrimination of intra- and inter-specific odor cues by male moths while locating a mate have been a focal point of research on insect olfaction 
(Hildebrand and Shepherd 1997; Roelofs 1979; Vickers et al. 1998). Much less effort has been devoted to the study of olfactory processing in female moths.

Nevertheless, many behavioral studies have revealed that odors play an important role in the life history of adult female moths. Several studies have recognized the importance of host plant odor in female oviposition site choice (Reviews in Bernays and Chapman 1994; Cardé 1984; Finch 1986; Murlis 1997; Murlis et al. 1992; Visser 1986). Female Heliothis virescens F. and Heliothis subflexa Guenèe have been shown to engage in upwind flight toward several different plant volatiles (Mitchell et al. 1991; Tingle and Mitchell 1992; Tingle et al. 1989). DeMoraes et al. (2001) demonstrated that nocturnal emissions from host plants under attack by $H$. virescens larvae were repellant to conspecific females. Female moths, therefore, use olfactory cues as an important element of host plant choice. Additionally, floral odors may be important for both location of adult food sources (nectar) and in evaluation of host plant quality (Bruce et al. 2002; Cunningham et al. 2004; Raguso and Willis 2002). Helicoverpa armigera females were attracted to traps baited with floral odor lures, and electroantennogram responses were elicited by exposure to floral odors (Bruce and Cork 2001).

In addition to plant volatiles, female moths may detect a multitude of additional odorants, including volatiles associated with conspecifics (Birch 1975; Birch et al. 1990; Fitzpatrick and McNeil 1988; Ochieng' et al. 1995). In $H$. virescens, male-produced hairpencil compounds are important in courtship, wherein females may reject males lacking the appropriate complement of odors (Hillier and Vickers 2004). Furthermore, in several species of insects, females may have receptors that respond to odors found in their own pheromone blend (den Otter et al. 1978; Hansson et al. 1989; Ochieng' et al. 1995; Seabrook et al. 1987). Females of Spodoptera littoralis have sensilla that respond to a component of the female-produced sex pheromone (Z)-9, (E)-11-tetradecenyl acetate (Ljungberg et al. 1993), while female Choristoneura fumiferana Clemens exhibit behavioral and electrophysiological responses to $(E)$-11-tetradecenal and $(Z)$-11-tetradecenal, components of the female-produced sex pheromone (Palaniswamy and Seabrook 1978). In these instances, it is not clear whether these receptors are specialized for pheromone reception or serve an alternative function and are coincidentally activated by pheromone components.

Male heliothine moths are considered more sensitive than females to female-produced pheromones, having a population of sexually dimorphic long trichoid sensilla specialized for reception of sex pheromones (Almaas and Mustaparta 1990; Almaas et al. 1991; Baker et al. 2004; Cossé et al. 1998; Ochieng' et al. 2003). In addition to the long trichoid sensilla, there is a complement of short trichoid sensilla present on both sexes that is thought to house olfactory receptor neurons (ORNs) sensitive to plant odors (Almaas and Mustaparta 1991).
The ORNs project to the antennal lobe (AL), the primary olfactory neuropil, and make synaptic connections with local interneurons and central projection neurons (PNs; Hansson 1997; Mustaparta 2002). The insect $\mathrm{AL}$ is organized into discrete glomeruli that are specialized for perception of particular odors (Hansson et al. 1992; Hansson and Christensen 1999; Hildebrand 1996; Hildebrand and Shepherd 1997; Vickers and Christensen 2003). In all moth species investigated to date, there is a specialized cluster of sexually dimorphic, male-specific glomeruli at the base of the antenna, known as the macroglomerular complex, or MGC (Berg et al. 1998; Christensen 1997; Christensen and Hildbrand 1987; Hansson et al. 1992, Todd et al. 1995; Vickers et al. 1998). The glomerular projections of pheromone-receptive ORNs have been traced to the male MGC of $H$. virescens using cobalt-lysine stains, linking peripheral physiological responses to individual glomeruli in the moth AL (Berg et al. 1998; Hansson et al. 1995). Furthermore, the structure and physiology of the MGC has been investigated through central recording of PNs in the AL and found to be organized differently between closely related heliothine species (Christensen et al. 1991, 1995; Vickers and Christensen 2003; Vickers et al. 1998). The organization of the MGC is specialized for the processing of attractive and repellent odors in the pheromone blends of closely related species, thus preventing cross-attraction and mating mistakes (Klun et al. 1979, 1980a, b, 1982; Quero and Baker 1999; Quero et al. 2001; Teal et al. 1981, 1986; Tumlinson et al. 1975; Vickers 2002).

In female $H$. virescens, two female-specific glomeruli, called the large female glomeruli (LFGs) are present at the base of the antennal nerve (Berg et al. 2002). While the physiology of the neurons associated with these glomeruli is not known in $H$. virescens, studies of LFG PNs in Manduca sexta L. have demonstrated that these glomeruli may be specialized for host odor processing (King et al. 2000; Shields and Hildebrand 2001). The function and physiology of the remaining glomeruli that appear to be common to both the male and female AL is less understood, and few studies have documented physiological activity directly within the female AL (Anton and Hansson 1994; Carlsson et al. 2002; Masante-Roca et al. 2002; Meijerink et al. 2003). Galizia et al. (2000) found calcium-imaging responses evoked by several plant odors that were localized to similar regions of the AL in $H$. virescens males and females. In a more recent study, Skiri et al. (2004) used calcium imaging to record spatio-temporal responses to selected plant odors in the ALs of male and female $H$. virescens. These studies provide some indication of the possible sites for odor processing but were limited by the ability of calcium imaging to penetrate the $\mathrm{AL}$ and resolve activity in glomeruli beneath the AL surface.

The aim of this study was to determine the response spectrum of ORNs within sensilla on female $H$. virescens antennae to a variety of behaviorally relevant odorants. Additionally, we sought to determine the glomerular 
(Z9-16:Ald), (Z)-11-hexadecenyl acetate (Z11-16:OAc) and $(Z)$-11-hexadecenol (Z11-16:OH)) were obtained from Bedoukian Research Inc (Danbury, CT, USA). Solutions of hairpencil components (tetradecanoic acid $(14: \mathrm{OOH})$, hexadecanol $(16: \mathrm{OH})$, hexadecanyl acetate (16:OAc), hexadecanoic acid (16:OOH), octadecanol (18:OH), octadecanyl acetate (18:OAc) and octadecanoic acid $(18: \mathrm{OOH})$ ) were obtained from either Dr. James Tumlinson (Department of Entomology, The Pennsylvania State University, University Park, PA, USA), or purchased from Sigma Aldrich (St. Louis, MO, USA). Solutions containing floral odorants (benzyl alcohol, 2-phenyl ethanol, benzaldehyde, phenyl acetaldehyde and phenyl acetylene) and plant volatile (linalool, (Z)-3-hexenyl acetate (Z3-6:OAc), (Z)-3-hexenol (Z3-6:OH), (E)-2-hexenal (E2-6:Ald), $\beta$-caryophyllene and $\alpha$-humulene) solutions were kindly provided by Dr. Robert Raguso (Department of Biological Sciences, University of South Carolina, Columbia, SC, USA). All odorant solutions were stored in a freezer at $-20^{\circ} \mathrm{C}$. Samples of stock solutions were confirmed to be at $>95 \%$ purity by injection onto a Shimadzu GC 17A gas chromatograph equipped with a $30 \mathrm{~m} \times 0.25 \mathrm{~mm}$ ID DB-5 capillary column. All chemicals were diluted in hexane at decade steps from $100 \mathrm{ng}$ to $1 \mathrm{mg}$, with the exception of $16: \mathrm{OH}, 18: \mathrm{OH}, 16: \mathrm{OOH}$ and $18: \mathrm{OOH}$, which all became solid at room temperature at concentrations higher than $100 \mu \mathrm{g} / \mu \mathrm{l}$.

\section{Odorant stimulation}

Stimulus cartridges were made by applying $10 \mu \mathrm{l}$ of an odorant solution to a $5 \times 30 \mathrm{~mm}^{2}$ piece of filter paper in a $1 \mathrm{ml}$ plastic syringe. Stimulus loadings ranged from $100 \mathrm{ng}$ to $100 \mu \mathrm{g}$ for EAGs, and from $100 \mathrm{ng}$ to $1 \mathrm{mg}$ for single sensillum recording (SSR). Stimulation was automatically controlled by Labview $6.1^{\odot}$ software (National Instruments, Austin, TX, USA). A continuous flow of charcoal-filtered, humidified air was provided at a flow rate of $1 \mathrm{l} / \mathrm{min}$. To activate stimulation, a valve driver (Parker-Hannafin) was used to switch the airstream from the continuous flow to the stimulus cartridge. Both the stimulus and continuous flow were connected to a mixing chamber $(50 \mathrm{~mm}$ long $\times 5 \mathrm{~mm}$ inner diameter), with $20 \mathrm{~mm}$ of thin plastic straws inserted at the exit to smooth the flow exiting the chamber. The exit of the mixing chamber was positioned $10 \mathrm{~mm}$ away from the insect antenna. For EAGs, individual stimuli were presented in increasing concentration steps, beginning with $100 \mathrm{ng}$ and ending with $100 \mu \mathrm{g}$, and the order of the individual stimulus presentation was randomized. For SSRs, stimuli were presented in random order, and at a concentration of $100 \mu \mathrm{g}$ for initial screening of a sensillum, with at least $60 \mathrm{~s}$ between stimulation to prevent adaptation, and ensure that spike activity had returned to pre-stimulation levels. Between all stimulus presentations, a hexane blank was tested. Stimulation occurred as a series of three $100 \mathrm{~ms}$ puffs, separated by $1 \mathrm{~s}$ each. Two seconds of pre-stimulation and $1 \mathrm{~s}$ of post-stimulation data were recorded, resulting in six seconds total recording time for each stimulus presentation. Spike frequency was determined by counting the number of spikes during $1 \mathrm{~s}$ following each stimulus onset and standardized by subtracting the number of spikes during the first second of pre-stimulus recording time. For calculation of dose-response curves, the mean number of spikes across all the three stimuli was used (Main-effects ANOVA indicated no significant difference in the spike frequency of three consecutive stimuli).

\section{Electroantennogram recordings}

Electroantennograms were conducted on isolated antennae of both male and female $H$. virescens (Roelofs 1979; Schneider 1962). Antennae were excised at the scape using iridectomy scissors. The tip was cut at the distal 4-5th segment. Chloridized silver electrodes were inserted into the tip and the base of the antenna, and sealed with vaseline.

The EAG activity was filtered (HUMBUG ${ }^{\circledR}$, Quest Scientific), amplified $1,000 \times\left(\right.$ ER- ${ }^{\circledR}{ }^{\circledR}$, Cygnus Technology), monitored on an oscilloscope (GOS-620FG ${ }^{\circledR}$, Instek) and data recorded using a Rec-Wise software program (written by C.K.) in Labview $6.1^{\circledR}$. The integration above each EAG curve was recorded, and standardized by subtracting the consecutive hexane blank in a series. The EAG integration values were normalized between males and females by expressing all responses as a percentage of the mean response to a $100 \mathrm{ng}$ linalool stimulus for each sex (set at 100\%). EAG responses were compared using a nested ANOVA comparing sex, odor and concentration effects. Means were separated using a Fisher's Least Significant Difference test $(P<0.05)$. Statistical analyses were conducted using Statistica ${ }^{\odot}$ (StatSoft Inc., 1999).

Single sensillum recordings (SSRs)

Electrophysiological responses of ORNs in individual sensilla were conducted using a cut sensillum technique (Kaissling 1974; Van der Pers and den Otter 1978). Individual moths were restrained in $1 \mathrm{ml}$ cut disposable pipette tips, and their heads held in place with dental wax. The moths were placed horizontally on a depression slide, and the tip of the antenna was fastened to the side of the slide using water-soluble correction fluid (Liquid Paper ${ }^{\circledR}$, Paper Mate). Once the moth was secured, a silver chloride reference electrode was inserted into the contra-lateral eye.

Prepared moths were mounted on a compound microscope $\left(\right.$ Wild $^{\circledR}$ ) and viewed at $20 \times$. The rig was mounted on an anti-vibration table, and shielded with a Faraday cage. Sensilla were cut using a thin glass capillary mounted to a piezo crystal, which was connected 
to a function generator. The glass capillary resonated at high speed by altering the frequency and amplitude of the signal from the function generator to the soundemitting piezo as described by Gödde (1989). This tool was then used to cut the distal $20 \%$ of a sensillum by advancing the vibrating glass capillary on a micromanipulator. Sensilla were randomly selected from the proximal ventral surface of the antenna. Once cut, the cutting tool was removed from the micromanipulator and replaced with a headstage recording electrode, and was placed over a single sensillum. The recording electrode consisted of a chloridized silver wire in a salinefilled glass capillary.

Previous research has shown that only a single morphological subtype of sensilla trichodea (length 30$50 \mu \mathrm{m}$ and diameter $2 \mu \mathrm{m}$ ) is present on the antenna of female $H$. virescens, thus preventing any confusion between morphologically distinct sensillar subtypes (Almaas and Mustaparta 1990). This is also the case in Helicoverpa assulta, wherein only a single morphological subtype of s. trichodea has been described in females (Koh et al. 1995). Moreover, the length and diameter of these s. trichodea made them easy to discriminate from other sensilla such as larger sensilla chaetica or much shorter sensilla basiconica ( $<10 \mu \mathrm{m}$ length).

Following presentation of the complement of odorants, if the signal was sufficiently strong, responding ORNs were tested again to obtain dose-response curves for stimuli. Odors were presented from low to high concentrations from $100 \mathrm{ng} / \mu \mathrm{l}$ to $1 \mathrm{mg} / \mu \mathrm{l}$ (except for previously noted compounds which solidified at concentrations greater than $100 \mu \mathrm{g} / \mu \mathrm{l})$. ORN activity was filtered and amplified $(1,000 \times)$ using similar equipment, software and protocols as in EAG experiments. In instances where it was suspected more than one ORN might be present, spike amplitudes were also examined. Filtering, spike detection and analysis were also performed using programs written by $\mathrm{C}$. K. on Labview $6.1^{\circledR}$. A main effects ANOVA was used to determine significant differences in spike frequency based on odorant, concentration or stimulus number $(1,2$ or 3$)$, and means were separated using Fisher's LSD test.

\section{Staining of sensory neurons}

Once the physiology of ORN(s) within a sensillum was characterized, attempts were made to stain any neuron(s) through a cobalt-lysine staining procedure (Hansson et al. 1995; Todd et al. 1995; Todd and Baker 1996). For sensilla selected for staining with cobaltlysine solution, the saline-filled recording electrode was replaced with an electrode containing $0.5 \mathrm{M}$ solution of cobalt lysine ( $2.38 \mathrm{~g}$ cobaltous chloride with $5 \mathrm{~g}$ L-lysine in $20 \mathrm{ml}$ of distilled water, lowered to a $\mathrm{pH}$ of 7.2-7.4 using concentrated $\mathrm{HCl}$ ). Preparation of this solution has been described previously (Ochieng' et al. 1995; Hansson et al. 1995; Todd et al. 1995). ORNs were stimulated with an appropriate odorant for $10 \mathrm{~min}$
(100 ms 'puff' every $2 \mathrm{~s}$ ) and the electrode was allowed to remain in contact with the sensillum for a total of $1 \mathrm{~h}$ (in cases where several odorants activated the sensillum, the odor to which the neuron responded most sensitively was selected for stimulation). After $1 \mathrm{~h}$, the moth was removed to a petri dish with moistened paper toweling, and placed in a $4^{\circ} \mathrm{C}$ refrigerator for $48 \mathrm{~h}$. The brain was dissected from the moth and placed in a saline solution with 3-6 drops of ammonium sulfide on a rotator for 10 min. The brain was rinsed 3-4 times in saline, and fixed overnight in AAF [100\% Alcohol: Acetic acid: $38 \%$ Formaldehyde (8:1:2)] fixative. The next day, brains were rinsed three times in $96 \%$ ethanol, and stored in $70 \%$ ethanol in the refrigerator until silver intensification procedures could be performed.

Brains were subjected to Timms silver intensification (Timm 1958) for 20-30 min. Following intensification, brains were serial dehydrated in ethanol and embedded in Spurrs resin. Embedded brains were sectioned at $10 \mu \mathrm{m}$, and placed on subbed slides. Slides were counterstained using a modified solution of Lee's methylene blue-basic fuchsin solution (methylene blue + Azure II in borate) $: 0.5 \%$ Basic Fuchsin in 95\% ethanol:100\% ethanol $=1: 2: 1$ (S.G. Lee, personal communication). Slides were coverslipped and observed at $20-40 \times$ on a compound microscope with an Optronics Microfire ${ }^{\circledR}$ digital camera attached.

\section{Digital reconstructions}

Digital images of serial sections were taken at $20 \times$ to provide the branching pattern and glomerular projections of the stained ORNs, and perform reconstructions of the AL. Reconstructions were made in a 'Single Blind' format, wherein the brains were coded as image files and reconstructed without knowledge of their ORN responses. Digital images were saved as TIFF files and imported to AMIRA 2.3 ${ }^{\mathrm{TM}}$ (Indeed GmbH, Berlin; http://www.amiravis.com) for reconstruction. Individual glomerular boundaries and the outline of each of the whole AL from each section were traced with an image segmentation tool that permitted 3D grouping of labeled materials for each glomerulus. Reconstructed ALs and stained ORN projections were compared visually against previously constructed models of female ALs and identified using the $H$. virescens $\mathrm{AL}$ atlas (Berg et al. 2002). Images and digital reconstructions were exported to Adobe Photoshop 6.0, labeled and adjusted for brightness and contrast where necessary.

\section{Results}

\section{Electroantennogram recordings}

Comparison of electroantennogram responses between male and female H.virescens indicated distinct differences between sexes for many of the odorants tested 

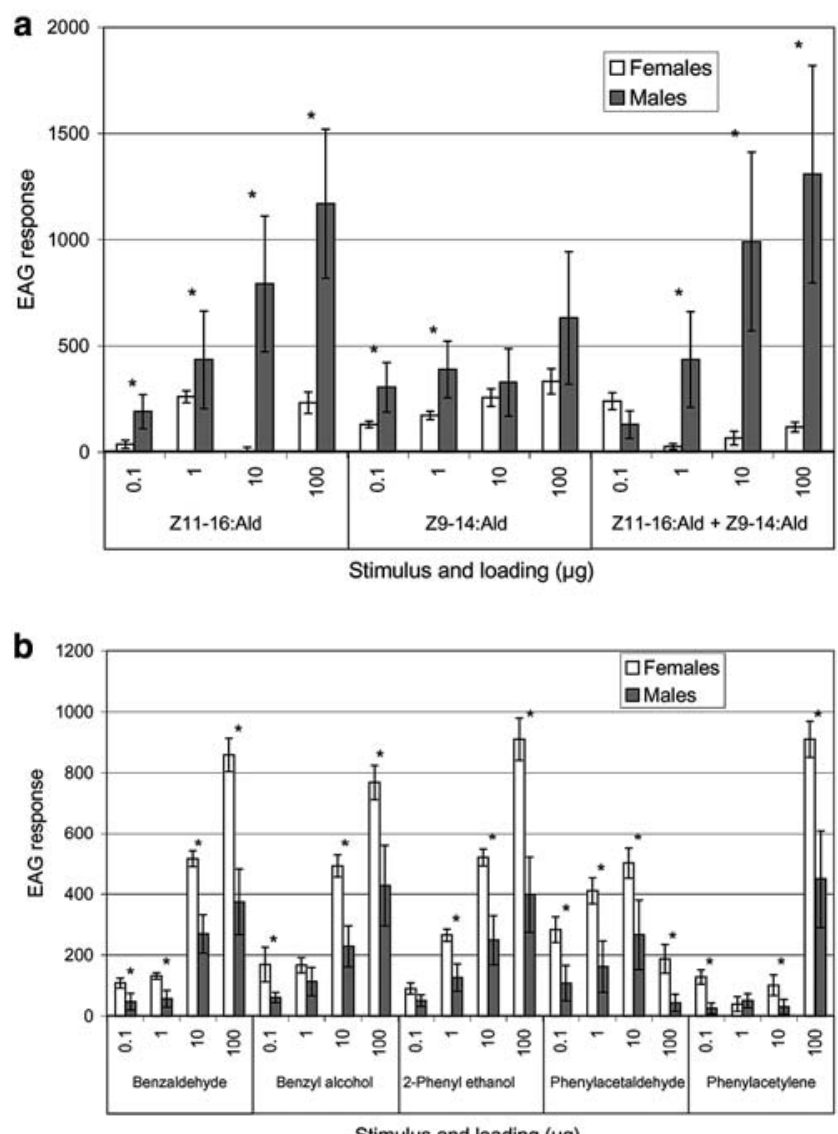

Fig. 1 Electroantennogram $(\mathrm{EAG})$ responses from male $(N=10)$ and female $(N=10)$ Heliothis virescens. All responses were standardized to a hexane blank before analysis, and subsequently normalized as a percentage of a response to $100 \mathrm{ng}$ linalool stimulus (measured as $100 \%$ ) for each sex. Responses to: a Female $H$. virescens sex pheromone components (blend of Z11 16:Ald and

(Fig. 1a-d). Concentration-dependent increases in EAG response were found in both sexes to most odorants, yet the magnitude of the response to different odors varied between the sexes $\left(\mathrm{F}_{1,18}=4.1, P<0.001\right)$. Male responses to female sex pheromone components Z1116:Ald and Z9-14:Ald were significantly greater than female responses; however, females also showed responses to both compounds, particularly Z9-14:Ald. Several hairpencil components produced larger EAG responses in females than in males, notably: 16:OAc, 16: $\mathrm{OH}, 18: \mathrm{OAc}$ and 18:OH. Female responses were significantly greater than males for benzaldehyde, benzyl alcohol, 2-phenyl ethanol and phenyl acetaldehyde. Female EAG responses were also significantly higher than male responses when stimulated with plant volatiles known to be induced by feeding damage, particularly linalool and Z3-6:OH.

\section{Single sensillum recordings}

Single sensillum recordings were made from 157 female $H$. virescens antenna with good electrical contact and
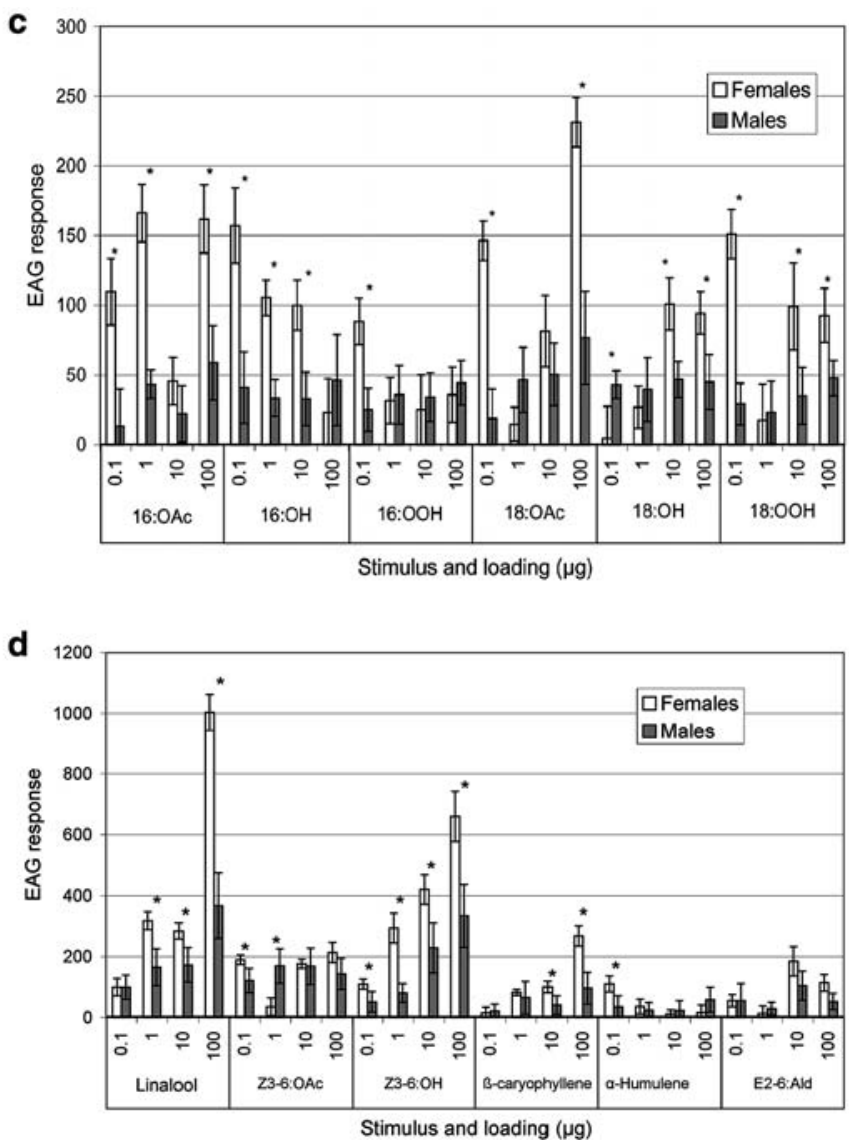

Z9 14:Ald at a ratio of 90:10, concentration represents loading of Z11 16:Ald); b Floral volatiles; c Male $H$. virescens hairpencil components; and d Induced plant volatiles.Asterisks indicate significant differences between mean male and female EAG responses $(P<0.05$, Fisher's LSD)

viable ORNs present in 955 sensilla trichodea. Of those sensilla screened, 184 exhibited clear responses to the odorants tested, with 25 possible 'sensillar types' identified based upon response profiles of ORNs therein (Table 2). Twenty out of the 22 odorants tested elicited responses from ORNs in one or more sensillar types. Surprisingly, 16:OOH and 18:OOH, both found in male $H$. virescens hairpencil extracts did not elicit responses from ORNs in any of the sensilla contacted. There was no specialization of sensillar types noted by the position on the antenna.

Many of the 25 sensillar types could be grouped based on ORN responses to four 'categories' of odors tested (hairpencils, female sex pheromones, florals and induced plant volatiles; Tables. 1,2). Two sensillar types housed ORNs responding to male hairpencil components, four to female heliothine sex pheromone components, three to floral plant odors and seven to induced plant volatiles (Table 2). Four sensillar types contained ORNs that responded to a combination of floral and plant volatiles, and five other sensillar types were found in which ORNs exhibited broad responses to several different types of odor. 
Table 2 Response profiles for 25 sensillar types identified from 157 H.virescens females through cut sensillum recording

\begin{tabular}{|c|c|c|c|c|c|c|c|c|c|c|c|c|c|c|c|c|c|c|c|c|c|c|c|c|c|c|}
\hline \multirow[b]{3}{*}{\begin{tabular}{|l|} 
Stimuli \\
\end{tabular}} & \multicolumn{26}{|c|}{ Sensillar type } \\
\hline & \multicolumn{2}{|c|}{ Hairpencil } & \multicolumn{4}{|c|}{ Female pheromone } & \multicolumn{3}{|c|}{ Floral odors } & \multicolumn{7}{|c|}{ Induced plant volatiles } & \multicolumn{4}{|c|}{ Floral and Plant } & \multicolumn{5}{|c|}{ Broadly tuned } & \\
\hline & 1 & 2 & \begin{tabular}{|c|}
3 \\
\end{tabular} & 4 & 5 & 6 & 7 & 8 & 9 & 10 & 11 & 12 & 13 & 14 & 15 & 16 & 17 & 18 & 19 & 20 & 21 & 22 & 23 & 24 & 25 & \\
\hline \multicolumn{27}{|l|}{ Pheromone Components: } \\
\hline Z11-16:Ald & & & & & $*$ & & & & & & & & & & & & & & & & & & & $\ldots$ & $*$ & \\
\hline Z9-14:Ald & & & $*$ & $*$ & $\cdot$ & & & & & & & & & & & & & & & & & $*$ & $\cdot$ & $*$ & .*** & \\
\hline Z11-16:OAc & $m$ & & & & & & & & & & & & & & & & & & & & & & $\cdot$ & $*$ & $*$ & \\
\hline $\mathrm{Z} 11-16: \mathrm{OH}$ & & & & & $\cdot$ & $\cdot$ & & & & & & & & & & & & & & & $\cdot$ & & & & $*$ & \\
\hline Z9-16:Ald & & & & $\cdot$ & $\cdot$ & & & & & & & & & & & & & & & & & & & $*$ & $*$ & \\
\hline \multicolumn{27}{|l|}{\begin{tabular}{|l|} 
Hairpencil Components: \\
\end{tabular}} \\
\hline $16: \mathrm{OAc}$ & $* *$ & & & & & & & & & & & & & & & & & & & & & & & $\ldots$ & $*$ & \\
\hline 18:OAc & $*$ & & & & & & & & & & & & & & & & & & & & & & & & & \\
\hline $16: \mathrm{OH}$ & & $*$ & & & & & & & & & & & & & & & & & & & & & & $\ldots$ & $*$ & \\
\hline $18: \mathrm{OH}$ & & & & & & & & & & & & & & & & & & & & & & & & $* *$ & $*$ & \\
\hline \multirow{2}{*}{\multicolumn{27}{|c|}{$16: \mathrm{OOH}$}} \\
\hline \multirow{2}{*}{\multicolumn{27}{|c|}{\begin{tabular}{|l|}
$18: \mathrm{OOH}$ \\
Floral odors: \\
\end{tabular}}} \\
\hline & & & & & & & & & & & & & & & & & & & & & & & & & & \\
\hline $\begin{array}{l}\text { Floral odors: } \\
\text { Benzyl alcohol }\end{array}$ & & & & & & & $* *$ & $\cdot$ & & & & & & & & & 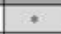 & $*$ & $*$ &. & $\cdot$ & & $*$ & & $* * *$ & \\
\hline Benzaldehyde & & & & & & & $\cdot$ & & & & & & & & & & $*$ &. & $\cdot$ &. & & & $\cdot$ & & $*$ & \\
\hline Phenyl acetaldehyde & & & & & & & $\cdot$ & & & & & & & & & & &. & $\cdot$ & $\cdot$ & & & & $*$ & ** & \\
\hline Phenyl acetylene & & & & & & & & & & & & & & & & & $\div$ &. &. & $\cdot$ & & & & & $*$ & \\
\hline 2-Phenyl ethanol & & & & & & & $\cdot$ & $\cdot$ & $\cdot$ & & & & & & & & $\cdot$ &. & $\cdot$ & $\cdot$ & & 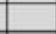 & $\cdot$ & & $*$ & \\
\hline \multicolumn{27}{|l|}{ Induced plant volatiles: } \\
\hline$\alpha$-humulene & & & & & & & & & & $*$ & & & & $\cdot$ & & & & & & & & & & & & \\
\hline Z3-hexenol & & & & & & & & & & . & 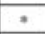 & &. & $* *$ & & & & &. &. & & & $*$ & & $* * *$ & \\
\hline E2-hexenal & & & & & & & & & & & & & & & 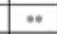 & & & & & $*$ & & & $*$ & & $*$ & \\
\hline Linalool & & & & & & & & & & & & $* *$ & $* *$ & & & & $* *$ & $\cdot$ & $*$ & $\cdot$ & $\cdot$ & $*$ & $*$ & & & \\
\hline B-caryophyllene & & & & & & & & & & . & & & $*$ & $*$ & $* * *$ & $* *$ & & & $\cdot$ & $*$ & & $=$ & & & $*$ & \\
\hline \multirow[t]{2}{*}{ Z3-hexenyl acetate } & & & & & & & & & $\cdot$ & . & $\cdot$ & & . & & & & & & $*$ & $*$ & &. & & & & \\
\hline & & & & & & & & & & & & & & & & & & & & & & & & & & Total \\
\hline Number of recordings & 54 & 7 & 45 & 24 & 3 & 3 & 2 & 4 & 1 & 1 & 5 & 8 & 8 & 2 & 2 & 5 & 1 & 1 & 2 & 1 & 1 & 1 & 1 & 1 & 1 & 184 \\
\hline Successful stains & 14 & 3 & 11 & 6 & 1 & 0 & 0 & 0 & 0 & 0 & 0 & 2 & 2 & 0 & 0 & 0 & 0 & 0 & 0 & 0 & 0 & 0 & 0 & 0 & 0 & 39 \\
\hline Number of stain attempts & 34 & 6 & 25 & 14 & 2 & 0 & 0 & 0 & 1 & 0 & 0 & 2 & 4 & 2 & 2 & 3 & 1 & 1 & 1 & 1 & 0 & 0 & 1 & 1 & 1 & 102 \\
\hline
\end{tabular}

Responses are indicated by asterisks in the boxes for corresponding odorants to the sensillar type, with $*=510 \mathrm{spikes} \mathrm{s}^{-1}, * *=1020$ spikes $\mathrm{s}^{-1}$ and $* * *=20$ or more spikes $\mathrm{s}^{-1}$ following a $100 \mathrm{~ms}$ pulse of $100 \mu \mathrm{g}$ of stimulus. Responses represent the relative increase in spiking above a threshold of spontaneous activity as standardized by a hexane control stimulus

Types 1, 3 and 4 (with ORNs responding to hairpencil and pheromone components) were the most abundant of the sensilla identified, revealing that $66 \%$ of the total sensilla contacted contained ORNs sensitive to conspecific odors. In most $(N=17)$ of the sensillar types identified, ORN responses were specific to four or fewer compounds within a given category. The remaining nine sensillar types (17-25) contained ORNs which were broadly tuned to a large number of odorants (3-18 odorants).

The intensity of ORN background firing varied between sensillar types. Most ORNs exhibited background firing rates of $1-3$ spikes $\mathrm{s}^{-1}$, with a few $(<5 \%)$ showing background activity as high as $10-12$ spikes $\mathrm{s}^{-1}$. Inhibitory responses were not noted to any of the odors tested. All ORNs responded in a relatively phasic manner, with some sensillar types having ORNs which maintained tonic firing for several seconds following stimulation, particularly at high stimulus loadings (Figs. 2, 3, $4,5)$. No significant effect $(P<0.05)$ was found due to consecutive presentation of the same odorant in any of the sensilla tested.

Most sensilla contained 1-2 active ORNs as determined by the separation of spike amplitudes, however, the possibility exists that additional silent or spontaneously active ORNs may have been present which were not detected, or could not be distinguished based on the spike amplitude. Unless otherwise noted, all spikes recorded from ORNs in a sensillar type were of similar amplitude.
Successful stains, wherein axonal projections could be visualized to their terminal arborizations within the individual glomeruli, were found in 39 of the 102 attempts, with stain present in 18 additional brains without clear arborizations. ORNs from seven different sensillar types were stained (Tables. 2 and 3), with successful stains primarily from type 1, 3 and 4 sensilla. Nineteen stains revealed uniglomerular axonal projections while 20 contained multiple ORNs projecting into different regions of the AL (Figs. 2, 3, 4, 5, 6, 8, 9). No stains were evident in tissues beyond the AL.

\section{Sensillar types responding to pheromonal odorants:}

The most common sensillar type, found in $29 \%$ of responses, were type 1 sensilla $(N=54)$, with an ORN that responded specifically to the male hairpencil components 16:OAc and 18:OAc, and to Z11-16:OAc (Fig. 2a-e). These ORNs were sensitive to stimulus loadings between $1 \mu \mathrm{g}-1 \mathrm{mg}$ and responded to no other odorants. No differentiation could be made between spike amplitudes for ORN responses in these sensilla, so it is possible that activity was present in a single ORN, potentially responding to specific compounds containing an acetate functional group (though no responses were noted to Z3-6:OAc). In a few instances $(N=5)$, a second, small spike amplitude ORN was present which did not respond to odor stimulation (not shown). 

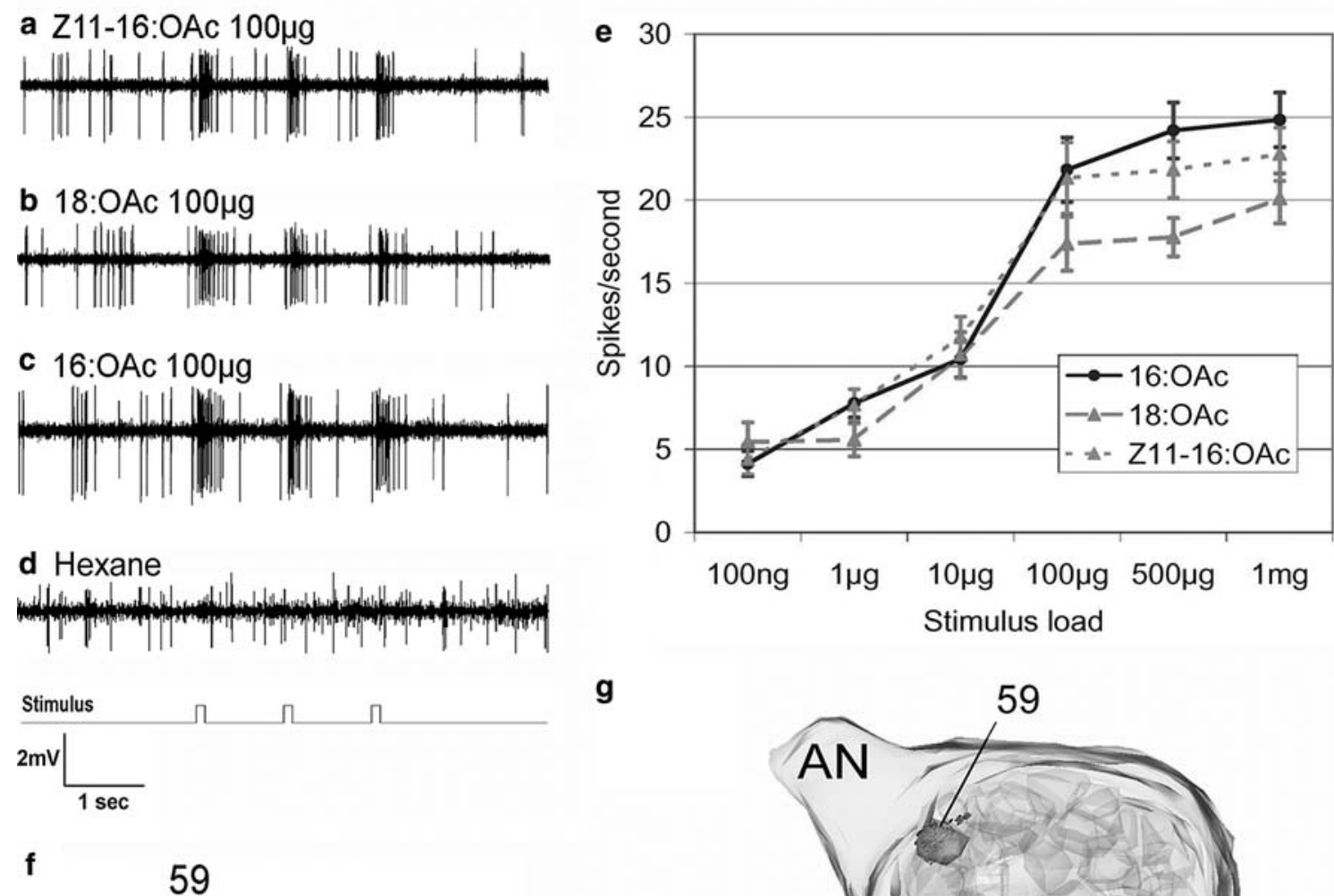

g
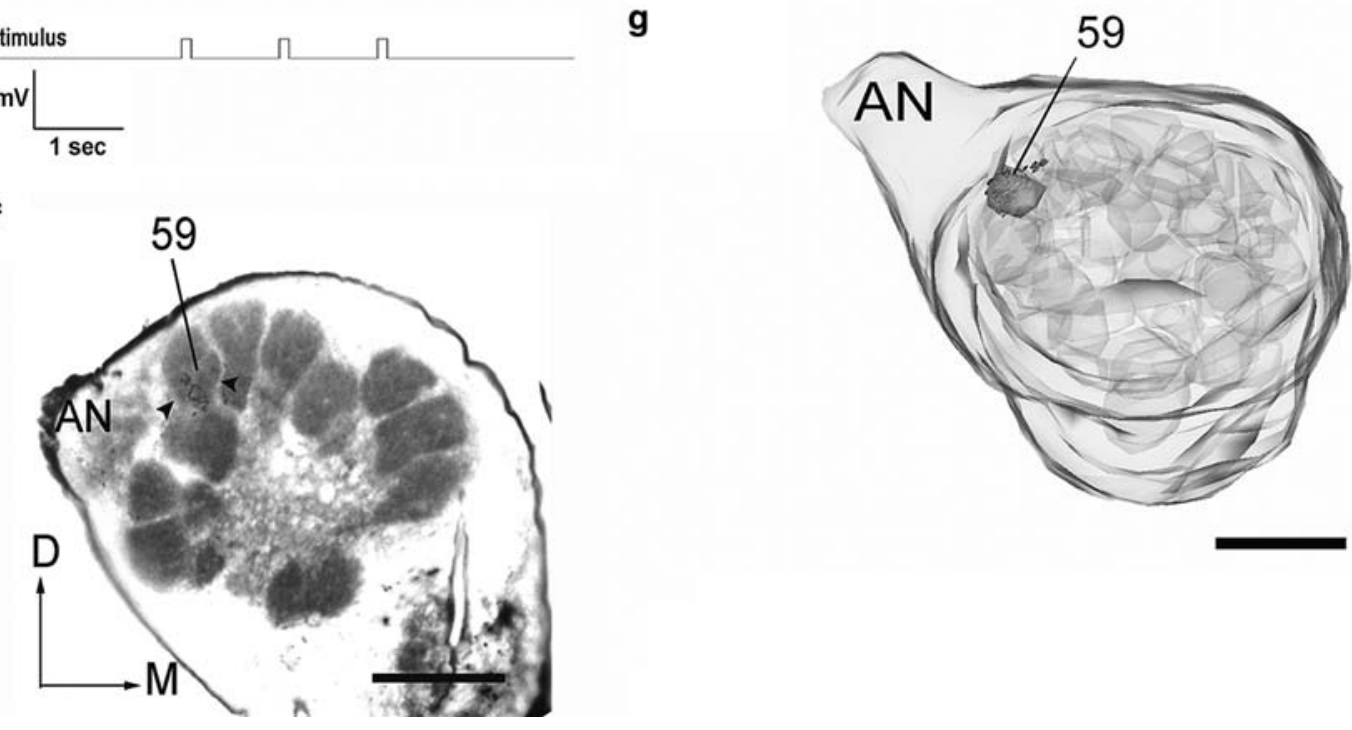

Fig. 2 Type 1 sensillum ORN responses, stain and 3D reconstruc tion. a d ORN response profile (original spike trains) from a female H.virescens type 1 sensillum, responding primarily to male produced hairpencil components: a Z11 16:OAc, b 18:OAc, c 16:OAc and $\mathbf{d}$ hexane blank. e Dose response curves from ORNs in type 1 sensilla $(N=15)$ stimulated with 16:OAc, 18:OAc and Z11 16:OAc. Six second total recording time, stimulus delivery

Type 1 sensilla showed an ORN with consistent arborization in glomerulus 59, anterior to the cLFG (Fig. 2). In 34 staining attempts, 14 successful stains were made. In six preparations, uniglomerular projections were noted to glomerulus 59 (Fig. 2f-g). Three preparations resulted in a pair of ORNs being stained and projecting to glomeruli 40 and 59 (Table 3). In two other preparations, double stains were also made to a pair of glomeruli: 48 and $59(N=1)$ and also to glomeruli 57 and $59(N=1$; Table 3$)$. Four other stains showed multiple projections, the first to glomeruli 3, 10 and 59, the second to 8,36 and 59 , the third to glomeruli 48 and
$3 \times 100 \mathrm{~ms}$ pulses. f g Cobalt lysine stain and $3 \mathrm{D}$ reconstruction of an ORN glomerular projection from a type 1 sensillum. Uniglomerular arborization in glomerulus 59, located antero laterally near the base of the antennal nerve $(N=6)$. Arrowheads indicate location of stain within micrograph. Dorsal $D$; Medial $M$. Scale bars $=100 \mu \mathrm{m}$

59 and the fourth to $2,11,19,31,59$ and 60 (Table 3 ). In the latter case, there may have been leakage at the electrode tip, causing adjacent sensilla to become loaded with cobalt lysine, and thus, non-informative glomeruli may have been stained. All type 1 stains included a projection to glomerulus 59 .

Seven type 2 sensilla were identified with ORNs which responded exclusively to $16: \mathrm{OH}$, a component of the male hairpencil pheromone (Fig. 3a-c). A second non-responsive ORN was also evident in all recordings from type 2 sensilla. In six attempts, three ORNs were stained which were excited by $16: \mathrm{OH}$ alone. All of the 
Table 3 Summary of projections identified from ORNs in sensillar types stained in female H.virescens

\begin{tabular}{|c|c|c|c|}
\hline Sensillar type & Physiology & $N$ & Glomerular projections \\
\hline \multicolumn{4}{|c|}{ Hairpencil components } \\
\hline \multirow[t]{7}{*}{ Type 1} & Z11 16:OAc, 16:OAc, 18:OAc & 6 & 59 \\
\hline & & 3 & 40,59 \\
\hline & & 1 & 48,59 \\
\hline & & 1 & 57,59 \\
\hline & & 1 & $3,10,59$ \\
\hline & & 1 & $8,36,59$ \\
\hline & & $1^{\mathrm{a}}$ & $2,11,19,31,59,60$ \\
\hline Type 2 & $16: \mathrm{OH}$ & 3 & 41 \\
\hline \multicolumn{4}{|c|}{ Female sex pheromone components } \\
\hline \multirow[t]{4}{*}{ Type 3} & Z9 14:Ald & 5 & $\mathrm{cLFG}$ \\
\hline & & 4 & 34, cLFG \\
\hline & & 1 & $40, \mathrm{cLFG}$ \\
\hline & & 1 & $40,51, \mathrm{cLFG}$ \\
\hline \multirow[t]{4}{*}{ Type 4} & Z9 14:Ald, Z9 16:Ald & 2 & 20 \\
\hline & & 1 & $17,20, \mathrm{cLFG}$ \\
\hline & & 2 & 20, cLFG \\
\hline & & 1 & $38, \mathrm{cLFG}$ \\
\hline Type 5 & $\begin{array}{l}\text { Z11 16:Ald, Z9 14:Ald (weak), } \\
\text { Z9 16:Ald (weak), Z11 16:OH (weak) }\end{array}$ & 1 & 60 \\
\hline \multicolumn{4}{|c|}{ Induced plant volatiles } \\
\hline Type 12 & Linalool & 2 & $36, \mathrm{mLFG}$ \\
\hline Type 13 & $\begin{array}{l}\text { Linalool, } \beta \text { caryophyllene, } \\
\text { Z3 hexenol, Z3 hexenyl acetate }\end{array}$ & 2 & 6 \\
\hline \multicolumn{2}{|c|}{ Total stains (from 102 attempts): } & 39 & \\
\hline
\end{tabular}

Glomerular positions indicated numerically from the H. virescens antennal lobe atlas (Berg et al. 2002). Consistent glomerular targets of axonal arborization are indicated in bold

${ }^{a}$ Possibly more than one sensillum stained

identified ORNs projected to glomerulus 41, located posterior to the cLFG (Fig. 3d, Table 3).

Type 3 sensilla ORNs $(N=45)$ were sensitive to Z914:Ald alone and showed no activity to other odorants (Fig. 4a-e). Eleven successful stains were made from ORNs in type 3 sensilla. Of these, five arborized only in cLFG, and the remainder showed multiglomerular stains between cLFG and other glomeruli (34, 40, 51; Fig. 4f-g, Table 3).

Type 4 sensilla ORNs $(\mathrm{N}=24)$ responded strongly to Z9-14:Ald at concentrations between $1 \mu \mathrm{g}$ and $1 \mathrm{mg}$, and had a higher activity threshold for Z9-16:Ald, responding to concentrations between $100 \mu \mathrm{g}$ and $1 \mathrm{mg}$ (Note, however, that Cossé et al. (1998) found that Z914:Ald is emitted at a ten times greater rate than Z916:Ald from similarly loaded cartridges. Therefore, taking into consideration the emitted stimulus rather than the cartridge loadings, the response threshold to each of these odorants may be more similar; Fig. 5a-f). Successful stains were made in 6 out of 14 attempts, with four different combinations of stained glomeruli. In these stains, some arborizations were either present medially in glomerulus 20 or in cLFG, with additional arborizations present in either glomerulus 17 or 38 (Fig. $5 \mathrm{~g}-\mathrm{h}$, Table 3 ).

Three type 5 sensilla contained ORNs responsive primarily to Z11-16:Ald, and slightly less sensitive to Z914:Ald, Z9-16:Ald and Z11-16:OH, principally at concentration loadings greater than $100 \mu \mathrm{g}$ (Fig. 6a-f). A single stain was made from a type 5 sensillum, showing a uniglomerular arbor to glomerulus 60, located anterior to glomerulus 59 (Fig. $6 \mathrm{~g}$ ). Type 6 sensilla $(N=3)$ contained ORNs which responded weakly to Z11-16:OH (Table 2).

Sensillar types responding to plant volatiles

Several ORNs responded weakly to floral odorants, particularly in sensilla that responded to a wide range of odors. ORN responses were noted to benzyl alcohol and 2-phenyl ethanol in types $7(N=2)$ and $8(N=4)$ sensilla (Fig. 7, Table 2). No differences in amplitude were evident between floral responses by ORNs within these types of individual sensilla. Type 8 sensilla also housed a non-responsive large amplitude spiking ORN. No ORN stains were obtained for sensilla responding to floral odorants. Attempted staining of type 9 sensilla was unsuccessful $(N=1)$.

Sensillar type $11(N=5)$ had small amplitude ORNs that responded to Z3-6:OH and Z3-6:OAc (Table 2). Similar ORN(s) are evident in several other sensilla (for example type 13), and ORNs in other sensillar types responded weakly to either Z3-6:OH or Z3-6:OAc, possibly indicating differentially responding ORNs which are common to several sensillar types. No ORN stains were obtained for type 11 sensilla.

Type $12(N=8)$ and $13(N=8)$ sensilla both had ORNs with strong responses to linalool at concentrations between $10 \mu \mathrm{g}$ and $1 \mathrm{mg}$ (Figs. 8, 9). Type 12 


\section{Hairpencil Odorants: Type 2}

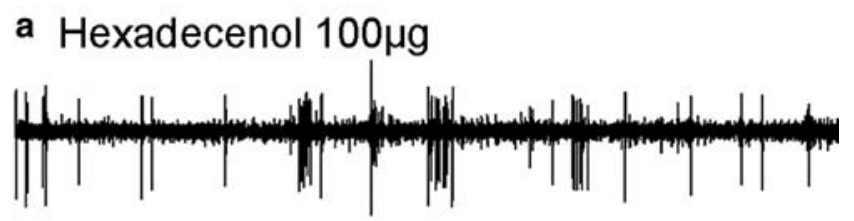

b Hexane
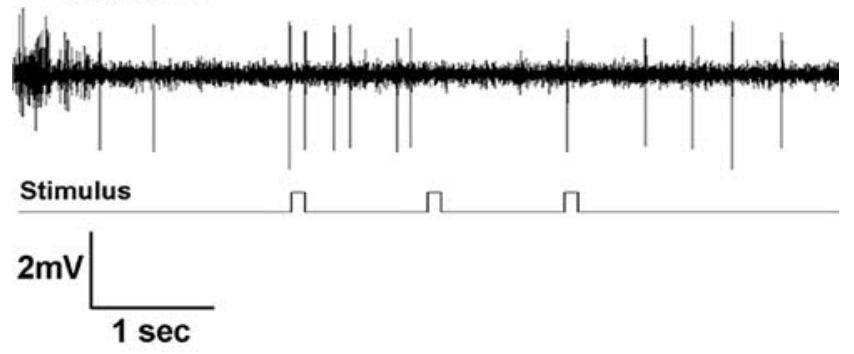

C

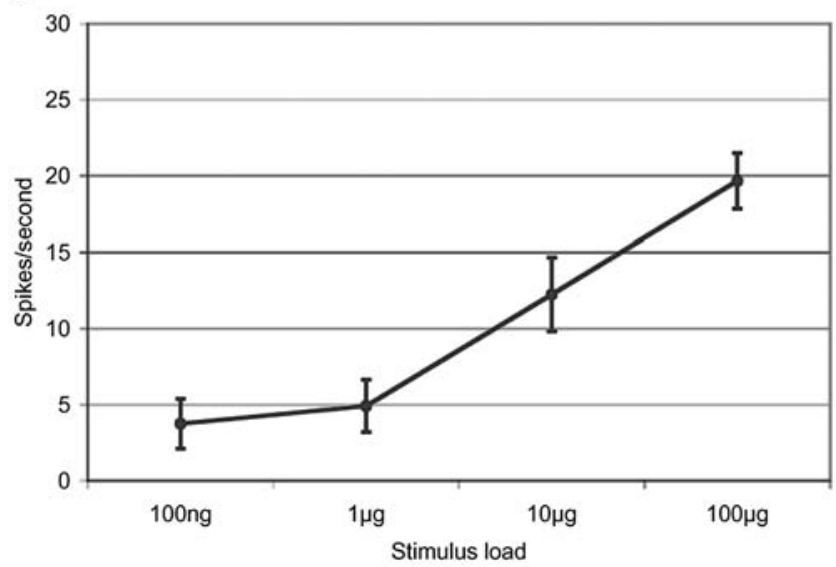

d

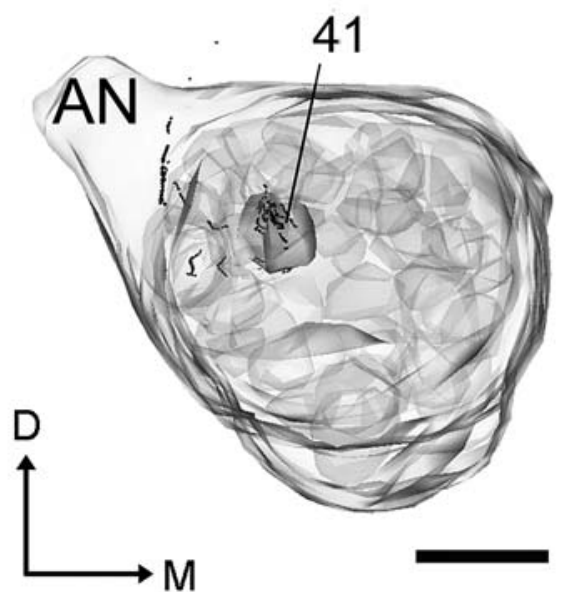

Fig. 3 Type 2 sensillum ORN responses and 3D reconstruction. a b ORN response profile (original spike trains) from a female H.virescens type 2 sensillum to: a $16: \mathrm{OH}$ and b hexane blank. c Dose response curves from ORNs in type 2 sensilla $(N=2)$ stimulated with $16: \mathrm{OH}$. Six second total recording time, stimulus delivery $3 \times 100 \mathrm{~ms}$ pulses. d $3 \mathrm{D}$ reconstruction of a cobalt lysine stain of an ORN from a type 2 sensillum showing a uniglomerular projection to glomerulus 41 (posterior lateral region of the AL; $N=3$ ). Dorsal $D$; Medial $M$. Scale bar $=100 \mu \mathrm{m}$
ORNs were only activated by linalool, whereas type 13 ORNs also had secondary responses to $\beta$-caryophyllene, Z3-6:OH and Z3-6:OAc (Figs. 8a-c, 9a-f). Two to three ORNs are evident in this sensillar type, one or more small spike amplitude ORN with responses to Z3-6:OH and Z3-6:OAc (Fig. 9c-d), a large spike amplitude ORN responding to linalool and $\beta$-caryophyllene and potentially a non-responsive ORN of similar amplitude. Two successful stains were made from ORNs in type 12 sensilla and projected to glomeruli $\mathrm{mLFG}$ and 36 (Fig. 8d-e). Two ORNs in type 13 sensilla were also stained projecting ventrally to glomerulus 6 (Fig. 9g). Attempted staining of ORNs in Type $14(N=2)$ and Type $16(N=3)$ sensilla was unsuccessful.

Neurons responding to $\beta$-caryophyllene were noted in several sensillar types. Type $16(\mathrm{~N}=5$; Fig. 10a-c) sensilla contained ORNs which responded exclusively to $\beta$-caryophyllene, while type $14(N=2)$ and $15(N=2)$ showed weaker responses to $\alpha$-humulene and Z3-6:OH or E2-6:Ald, respectively (Table 2). An additional small amplitude, non-responsive ORN was found only in type 15 sensilla.

Responses to various combinations of floral and plant volatiles were noted in some ORNs (sensillar types 17-20), possibly indicating co-localization of various ORNs found in sensillar types 7-16 (Table 2). No clear stains were obtained from floral or plant volatile responding ORNs in sensillar types 17-20.

\section{Broadly responding ORNs}

Five different sensilla housed ORNs responsive to a range of odorants ("Broadly tuned", Table 2). The ORN response spectra for most of these sensilla do not appear specialized for a particular functional group across the range of odorants tested, but exhibit portions of ORN response profiles found in other sensilla. For example, the response spectrum of type 19 encompasses the combined stimulus profiles for ORNs in sensillar types 7 and 13. Spike amplitudes were variable within all of the broad-spectrum sensilla, with typically two or more ORNs being excited by the complement of odors tested. Unfortunately, no successful stains were achieved from ORNs in these 'generalist' sensilla (types 21-25) which exhibited responses to odorants from several different categories.

\section{Discussion}

Single sensillum recording verified the presence of ORNs responding to all of the odorants tested, with the exception of 16:OOH and 18:OOH. Previous work has shown EAG activity to be an accurate means of estimating total ORN activation at the whole-antenna level, for a particular odorant (Dickens et al. 1993; Nagai 1983; Visser 1979). Assuming that EAG response largely 
Female Sex Pheromones: Type 3

a Z9-14:Ald $100 \mu \mathrm{g}$

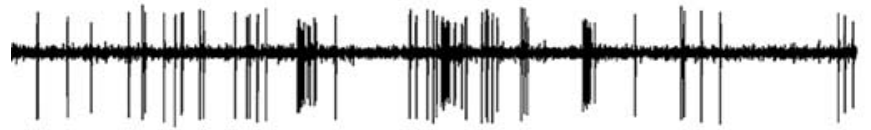

b Hexane

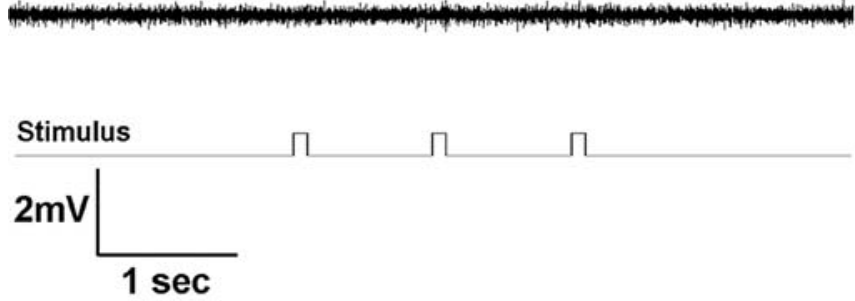

d

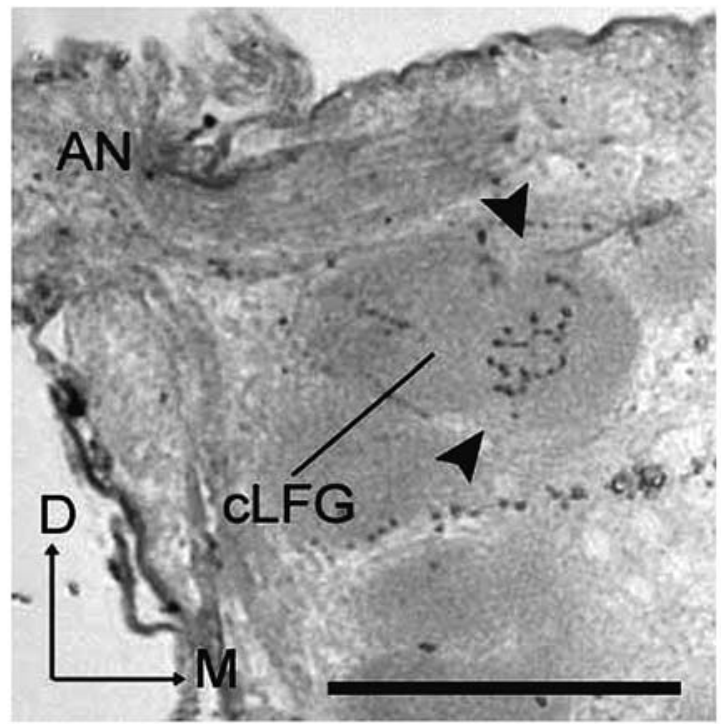

e

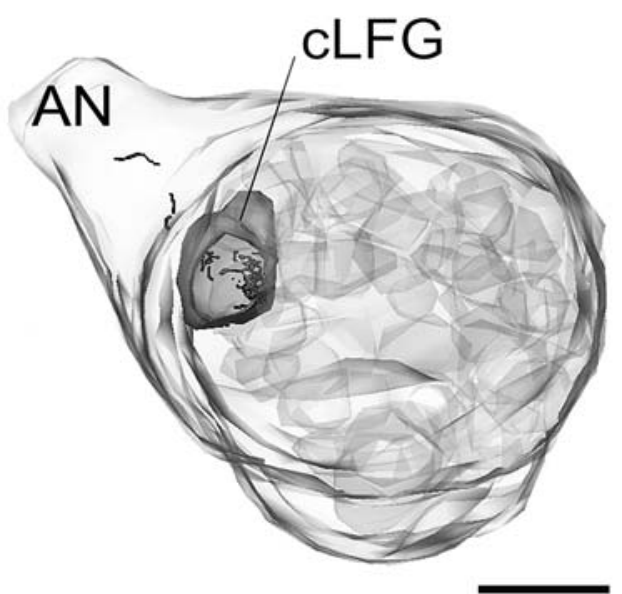

Fig. 4 Type 3 sensillum responses, stains and 3D reconstructions. a b ORN response profile (original spike trains) from a female $H$. virescens type 3 sensillum to: a Z9 14:Ald and b hexane blank. c Dose response curves from ORNs in type 3 sensilla $(N=19)$ stimulated with Z9 14:Ald. Six second recording time, stimulus delivery $3 \times 100 \mathrm{~ms}$ pulses. d g Cobalt lysine stains and $3 \mathrm{D}$ recon structions of ORN glomerular projections from Z9 14:Ald sensitive
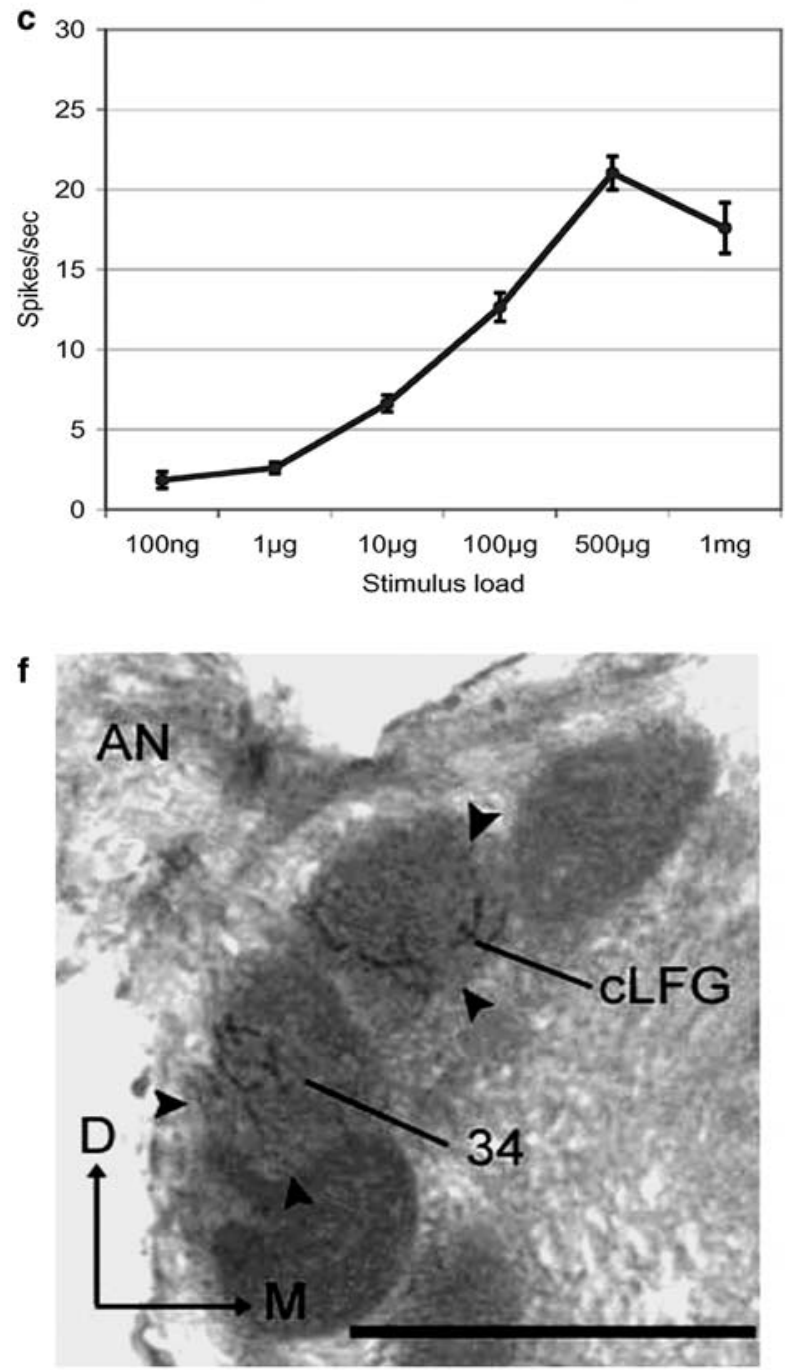

g

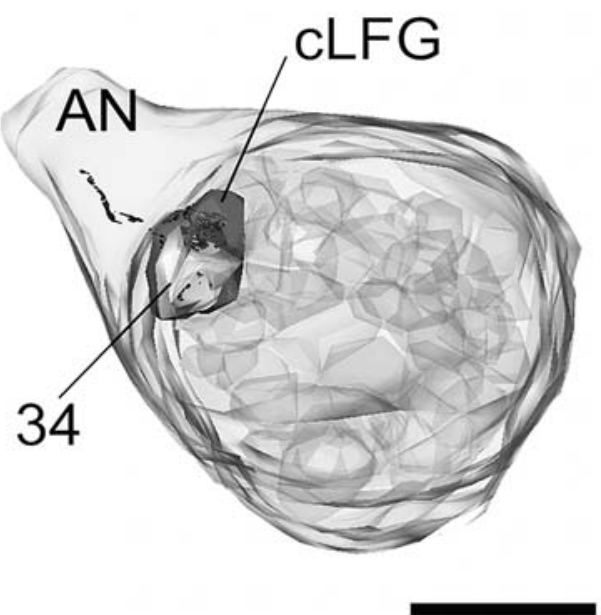

type 2 sensilla. d e Uniglomerular projection to cLFG (central Large Female Glomerulus) dorso laterally located at the base of the antennal nerve $(N=5)$. f g Example of a multiglomerular double stain indicating axons projecting to cLFG and the adjacent glomerulus $34(N=4)$. Arrowheads indicate location of stain within micrographs. Dorsal $D$; Medial $M$. Scale bars $=100 \mu \mathrm{m}$ 
a Z9-14:Ald $100 \mu \mathrm{g}$

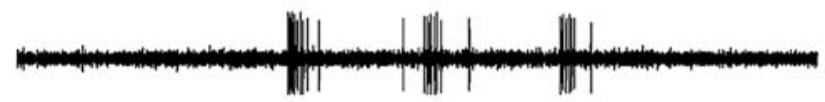

b Z9-14:Ald $500 \mu \mathrm{g}$

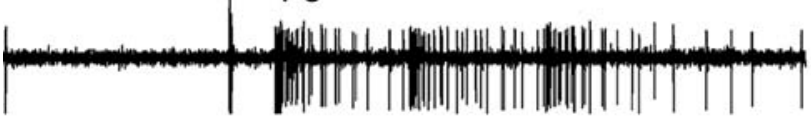

c Z9-16:Ald $100 \mu \mathrm{g}$
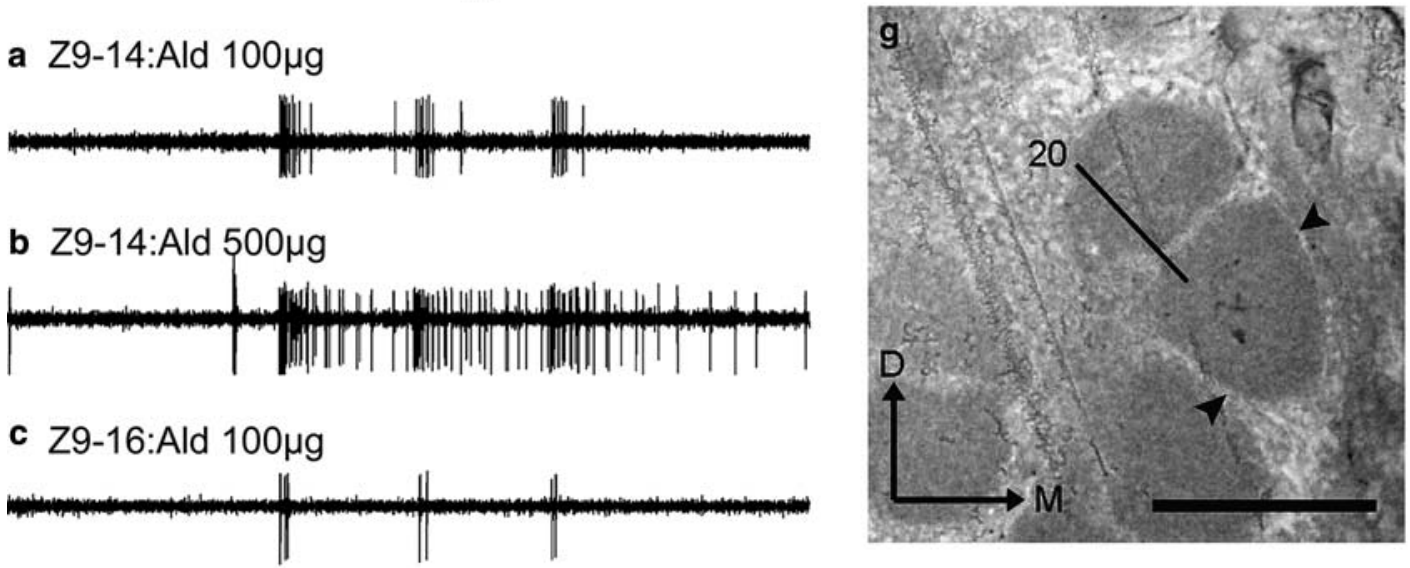

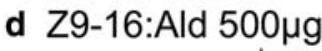

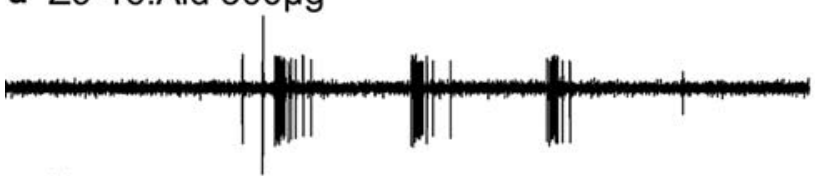

h

$$
\text { CLFG }
$$

\section{e Hexane}

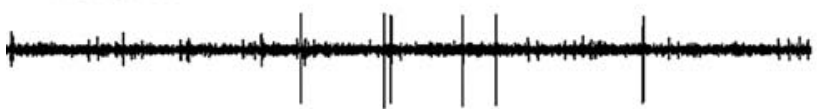

Stimulus
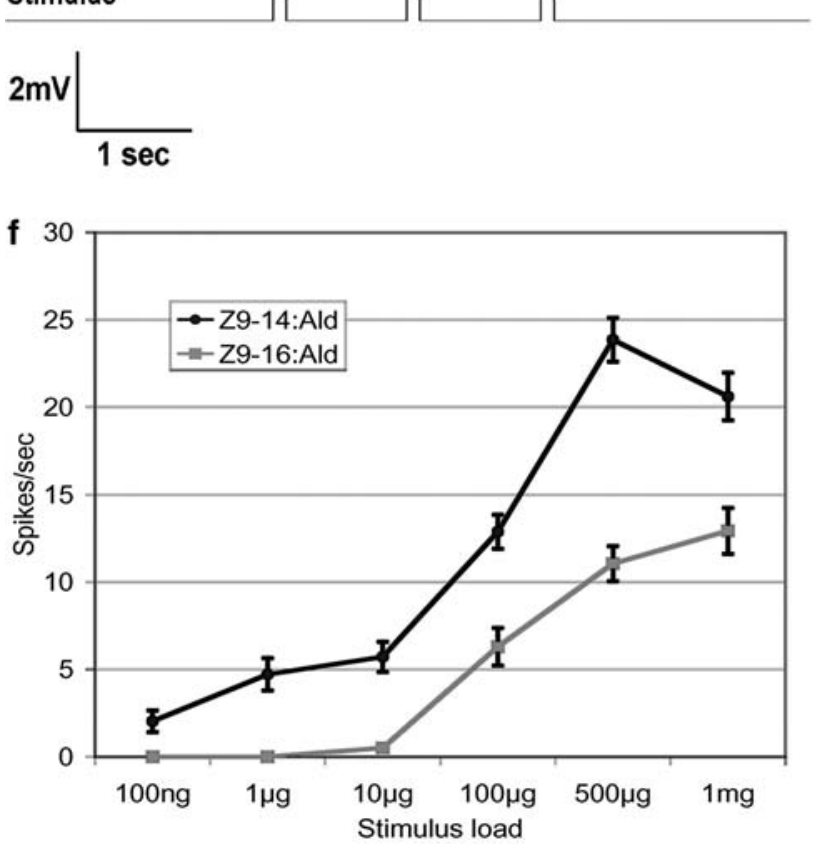

Fig. 5 Type 4 sensillum responses, stain and $3 \mathrm{D}$ reconstruction. a e ORN responses (original spike trains) from a female $H$. virescens type 4 sensillum to: a $100 \mu \mathrm{g}$ Z9 14:Ald, b $500 \mu \mathrm{g}$ Z9 14:Ald, c $100 \mu \mathrm{g}$ Z9 16:Ald, d $500 \mu \mathrm{g}$ Z9 16:Ald and e hexane blank. f Dose response curves from ORNs in type 4 sensilla $(N=12)$ stimulated with Z9 14:Ald and Z9 16:Ald. Six second recording time, stimulus delivery $3 \times 100 \mathrm{~ms}$ pulses. $\mathbf{g} \mathbf{h}$ Cobalt lysine stain and 3D

reflected a similar activation of the ORN population on both the male and female antenna, our results suggest that there is a variation in the complement of ORNs reconstruction of a double stain showing ORN axonal projections from a type 4 sensillum to cLFG (central large female glomerulus) and medially located glomerulus $20(N=2, \mathbf{g}$ is at a focal depth displaying stain in glomerulus $20,3 \mathrm{D}$ reconstruction also indicates location of concurrent stain in cLFG). Arrowheads indicate location of stain within micrograph. Dorsal $D$; Medial $M$. Scale bars $=100 \mu \mathrm{m}$

present between the sexes. This result contrasts with previous work on $H$. armigera (Hartlieb and Rembold 1996) and Agrotis segetum Denis and Schiffermüller 
Fig. 6 Type 5 sensillum responses and 3D reconstruction. a e ORN response profile (original spike trains) from a female $H$. virescens type 5 sensillum to: a Z11 16:Ald and with a lower response to: b Z9 14:Ald, c Z11 16:OH, and d Z9 16:Ald; e hexane blank. f Dose response curves from ORNs in type 5 sensilla $(N=12)$ stimulated with female $H$. virescens female sex pheromone components. Six second recording time, stimulus delivery $3 \times 100 \mathrm{~ms}$ pulses. g 3D reconstruction showing an ORN axonal projection from a type 5 sensillum to glomerulus 41 (near base of AN; $N=1$ ). Dorsal $D$; Medial $M$. Scale bars $=100 \mu \mathrm{m}$

(Hansson et al. 1989) in which the male and female moths demonstrated similar EAG responses to plantproduced volatiles. Not surprisingly, Z11-16:Ald and Z9-14:Ald elicited much higher EAG responses in male $H$. virescens, which have a large population of ORNs specific for each of these odorants (Almaas and Mustaparta, 1991; Baker et al. 2004). Based on EAG responses and the population of ORNs sampled in this study, some specialization of ORN populations on female antennae is likely. Males exhibited EAG responses to most of the odorants tested; however, the sensitivity to hairpencil components and plant volatiles was lower than that observed in female $H$. virescens. With the exception of specialized dimorphic glomeruli (MGC in males and LFGs in females), previous work has shown that there was a similarity between the structural position and number of glomeruli present, along with similar odor-evoked spatial response patterns observed using calcium-induced fluorescence to odorants tested in the male and female $H$. virescens (Berg et al. 2002; Skiri et al. 2004). The correspondence in AL structure between the male and female moths may suggest a functional homology in the glomeruli of both sexes, with variation in glomerular size being an indication of relative input from ORNs at the periphery (such as the large glomeruli of the MGC being due to the increased peripheral input of pheromone-sensitive ORNs). Both the variation in EAG responses and $\mathrm{AL}$ structure in $H$. virescens provide for the interesting prospect of investigating homology between the sexes in the complement of ORNs in short s. trichodea, and their projections to the glomerular array.

In many cases, the ORN response was clearly specialized to a specific odorant. This concurs with Stranden et al. (2003b) who found that a single sensillum in $H$. virescens females generally responded strongly to one or two odorants and weakly to others. Conversely, we also found that many sensilla also contained more general responses, with the presence of multiple ORNs conferring a more general response profile in some sensilla. Koh et al. (1995) have shown that as many as four ORNs may be co-localized in the same sensillum of H. assulta Guenée.

Recordings were attempted from 955 sensilla, with 771 sensilla non-responsive to the complement of odors tested (clean recordings, with spontaneous firing, but no odor-induced excitation). Additionally, some sensillar types contained silent or spontaneously firing ORNs
Female Sex Pheromones: Type 5
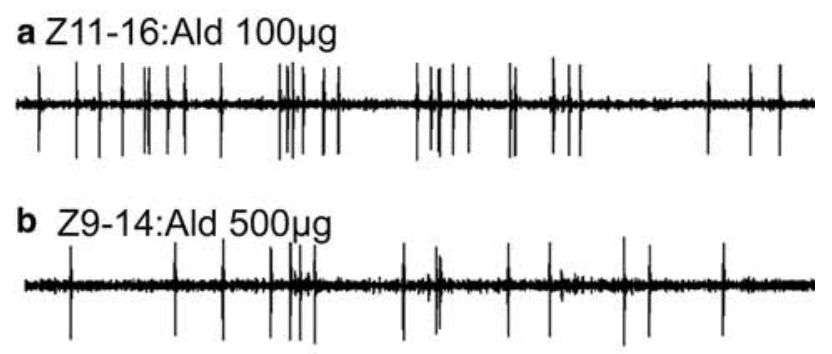

c $\mathrm{Z} 11-16: \mathrm{OH} 500 \mu \mathrm{g}$
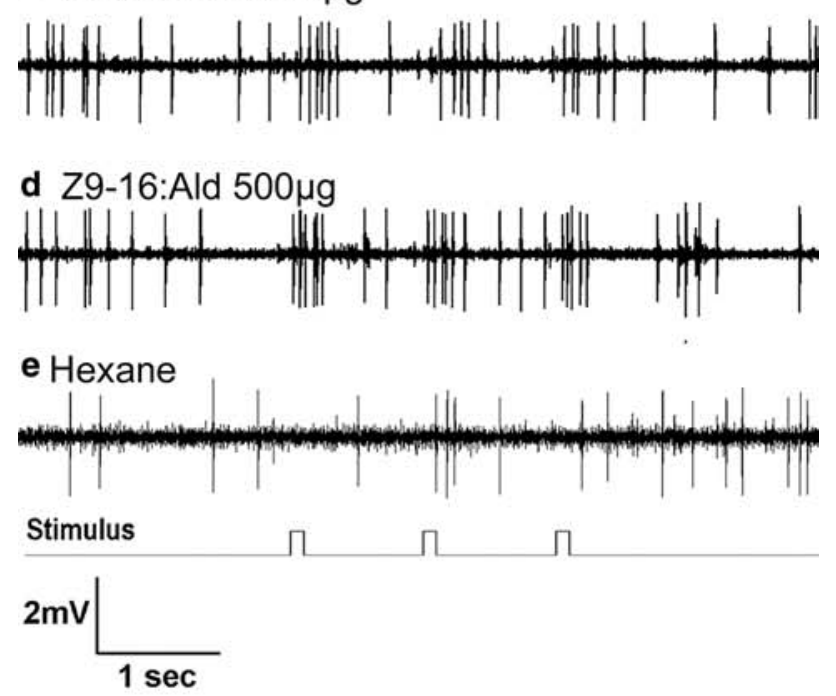

f

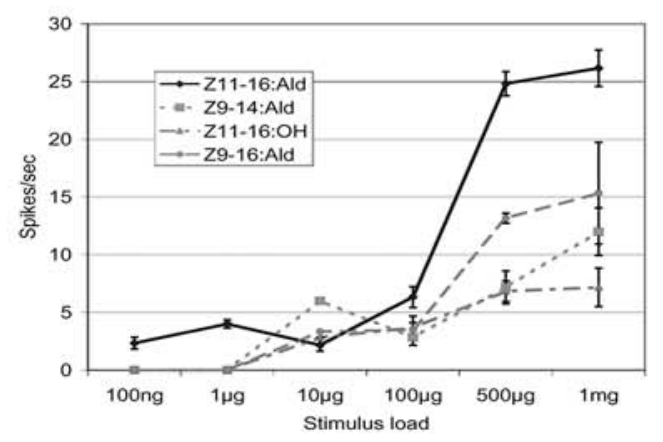

g

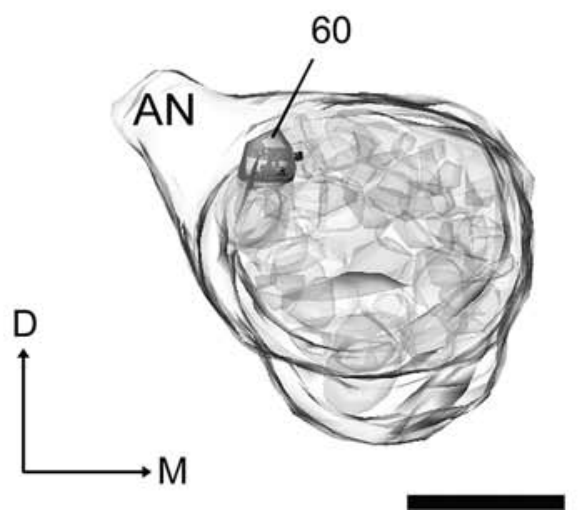

which were not sensitive to any of the odorants tested. This indicates that there are likely to be many more olfactory sensillar types present on the antenna than 
Fig. 7 Type 7 and type 8 sensillum responses. a e ORN responses (original spike trains) from a female $H$. virescens type 7 sensillum to: a benzyl alcohol, b 2 phenyl ethanol and with a lower response to $\mathbf{c}$ benzaldehyde and $\mathbf{d}$ phenyl Dose response curves from ORNs in type $8(N=4)$ sensilla responding only to $100 \mu \mathrm{g}$ of floral odors benzyl alcohol and 2 phenyl ethanol. Six second recording time, stimulus delivery $3 \times 100 \mathrm{~ms}$ pulses acetaldehyde; e hexane blank. f

Floral volatiles: Type 7

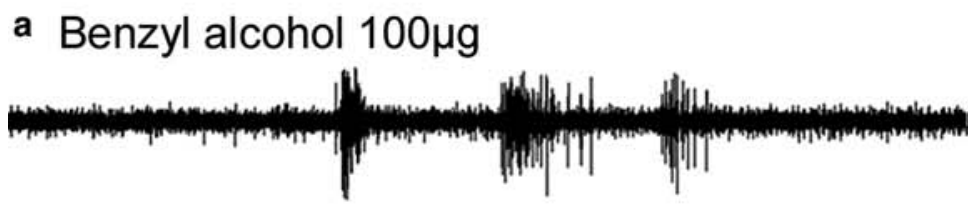

b 2-Phenyl Ethanol 500ug

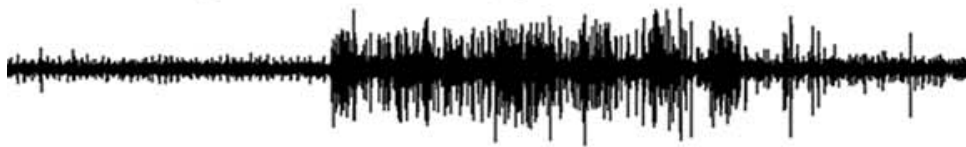

c Benzaldehyde $500 \mu \mathrm{g}$

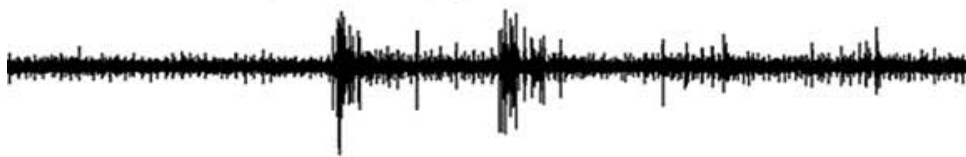

d Phenyl acetaldehyde $100 \mu \mathrm{g}$

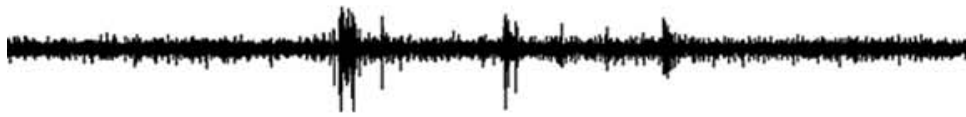

e Hexane
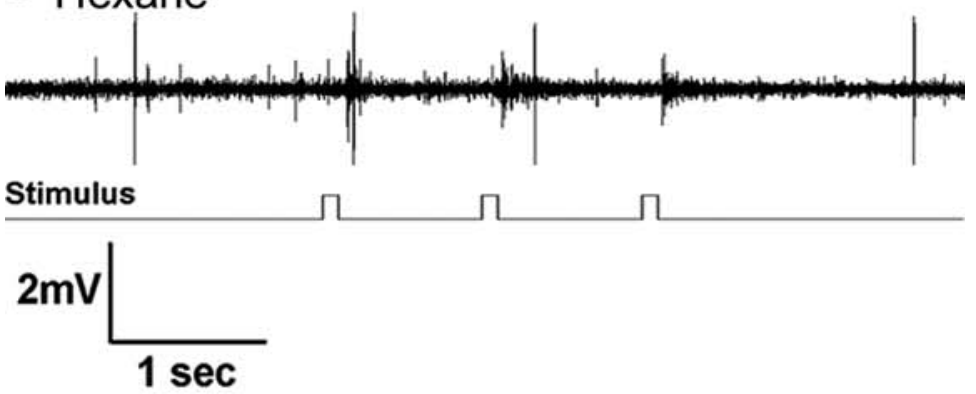

f Floral volatiles: Type 8

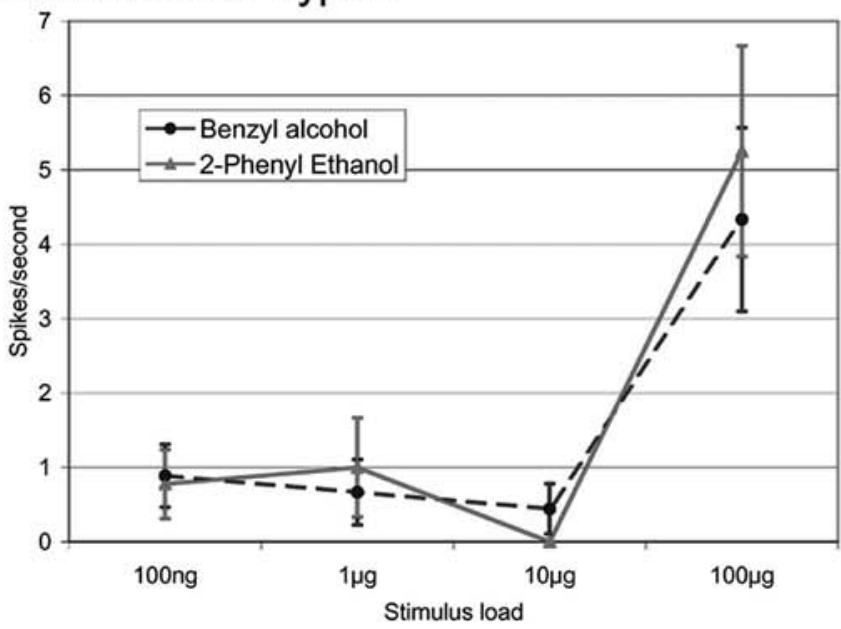

documented in this study. Stranden et al. (2003a, b) and Røstelien et al. (2000b) previously identified potential plant-sensitive ORNs on female $H$. virescens antenna. In particular, ORNs sensitive to (-) germacrene D were found in $80 \%$ of the sensilla tested (Røstelien et al. 2000a). Additionally, Stranden et al. (2003a, 2003b) 
a Linalool $100 \mu \mathrm{g}$

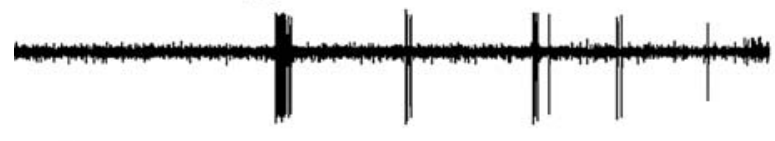

b Hexane
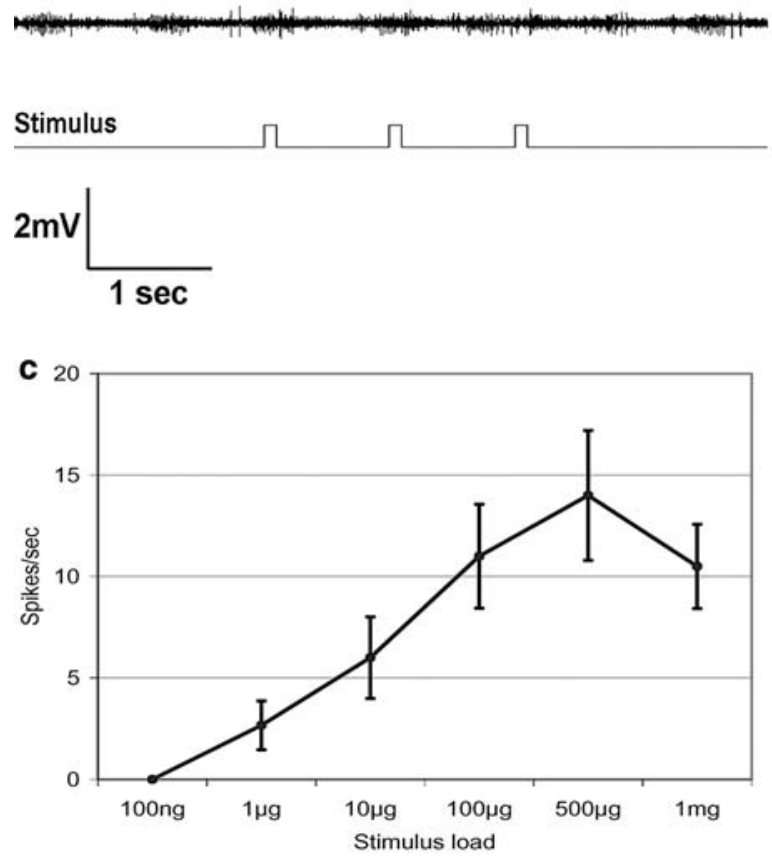

d

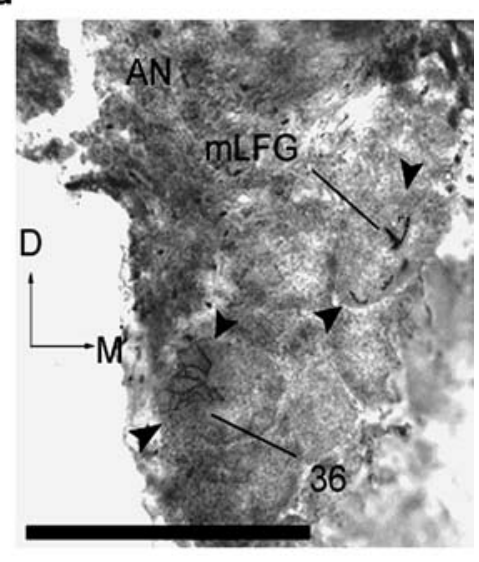

e

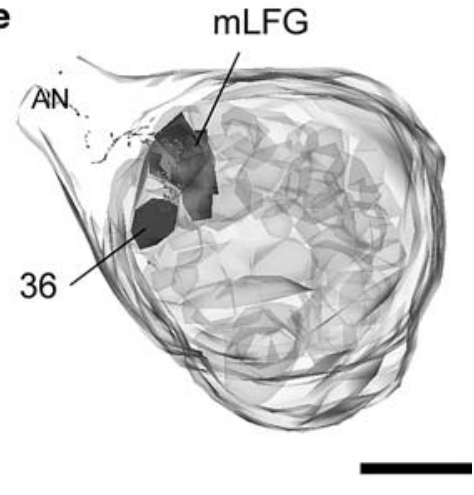

Fig. 8 Type 12 sensillum responses, stain and 3D reconstruction. a b ORN responses (original spike trains) from a female $H$. virescens type 12 sensillum to: a linalool; b hexane blank. c Dose response curves from ORNs in type 12 sensilla $(N=4)$ stimulated with linalool. Six second recording time, stimulus delivery $3 \times 100 \mathrm{~ms}$ pulses. d e Cobalt lysine stain and $3 \mathrm{D}$ reconstruction showing a double stain from a linalool sensitive type 12 sensillum, projecting to $\mathrm{mLFG}$ (medial large female glomerulus) and glomerulus 36 (both near the base of the AN; $N=2$ ). Arrowheads indicate location of stain within micrograph. Dorsal $D$; Medial $M$. Scale bars $=100 \mu \mathrm{m}$ found ORNs which were sensitive to several sesquiterpenes, E- $\beta$-ocimene, E,E- $\alpha$-farnesene, homo-farnesene and geraniol; co-localized within a sensillar type shared between three heliothine species. However, the behavioral relevance of these odorants has not been demonstrated in female $H$. virescens. Nevertheless, the non-responsive sensilla in the current study may have housed ORNs sensitive to other odorants, including those mentioned above, which were not utilized during the course of our experiments. More recently Røstelien et al. (2005) published descriptions of 14 ORN types sensitive to plant odors from $H$. virescens and $H$. armigera, many responsive to odorants not tested in our current study.

We have previously demonstrated that male hairpencil odorants are important in mate selection by female $H$. virescens (Hillier and Vickers 2004). Constituent components of these hairpencil blends include 16:OAc, 18:OAc and 16:OH (Teal and Tumlinson 1986); odorants for which we have now identified specific ORNs. Additionally, it is interesting to note that the type 1 sensillum is likely to contain a single ORN (as evidenced by several uniglomerular projections to glomerulus 59), which responds to 16:OAc, 18:OAc and Z11-16:OAc. This result indicates that the sensillum may be broadly tuned to 16-18 chain acetates, or is specifically tuned to these hairpencil compounds (no response was found to the shorter chain Z3-6:OAc). Our previous work has showed that when presented as individual compounds, 18:OAc appeared repellent to female $H$. virescens, while 16:OAc caused abdominal extension (Hillier and Vickers 2004). This study also found that the blend quality was important in mate choice, and therefore, combinations of odorants (and ORN activation) are probably significant in blend discrimination. Perhaps ORNs housed in other sensilla may act in concert with the type 1 sensilla, thereby facilitating discrimination between the 16- and 18-chain acetate.

Type 1 sensilla, at $29 \%$, were the most abundant sensillar type. In fact, $74 \%$ of the sensilla sampled were tuned exclusively to conspecific odorants, including hairpencil odorants and female-produced sex pheromone 
Induced Host Plant Volatiles: Type 13

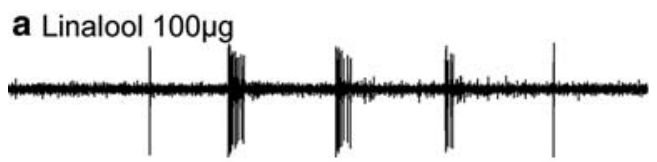

b ß-caryophyllene $500 \mu \mathrm{g}$

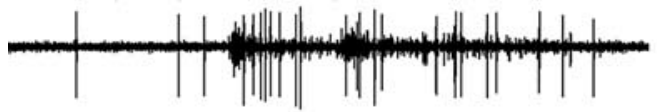

C (Z)-3-hexenyl acetate $500 \mu \mathrm{g}$

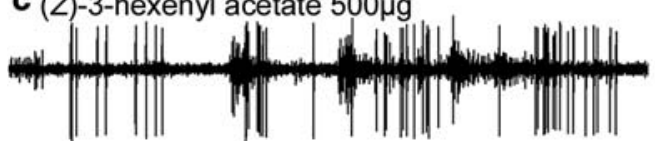

d (Z)-3-hexenol 500 $\mathrm{gg}$

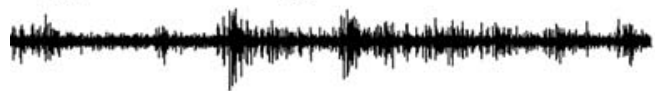

e Hexane

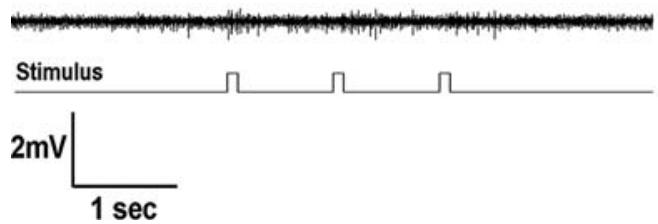

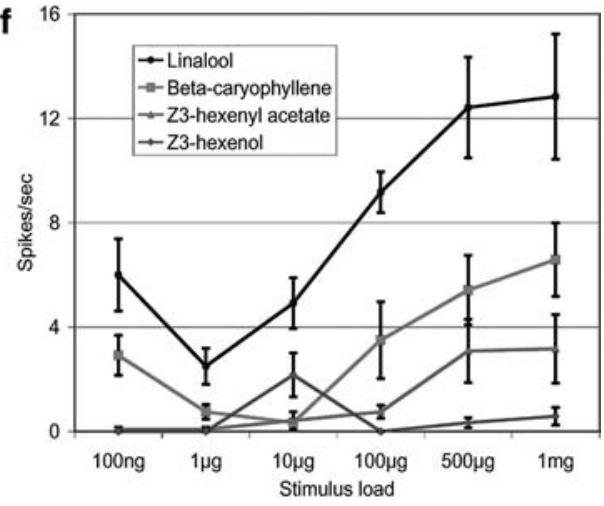

g

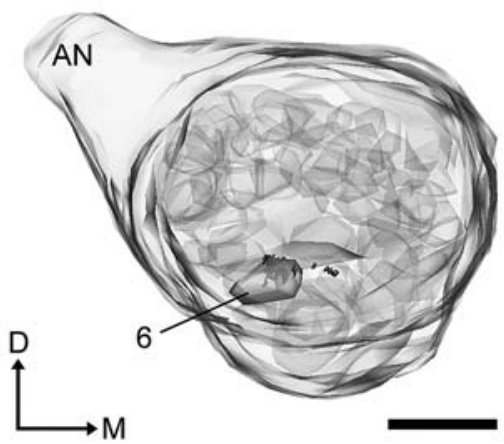

Fig. 9 Type 13 sensillum responses and 3D reconstruction. a e ORN responses (original spike trains) from a female $H$. virescens type 13 sensillum to: a linalool, b $\beta$ caryophyllene, c Z3 hexenyl acetate, $\mathbf{d} \mathrm{Z} 3$ hexenol and e hexane blank. f Dose response curves from ORNs in type 13 sensilla $(N=4)$ stimulated with plant volatile

components. EAGs from $H$. virescens females have also previously shown responses to many components of the female sex pheromone (Almaas and Mustaparta 1991). The presence of such an array of pheromone-sensitive receptors is surprising, given previous assumptions that short trichoid sensilla are primarily used for detecting non-pheromonal odors. Hansson et al. (1989) found that in the noctuid Agrotis segetum, female sensilla showed no response to the major female-produced sex pheromone components or their analogues (males of this species lack dimorphic pheromone-sensitive long trichoid sensilla). Studies on female $S$. littoralis demonstrated a similar pattern as $H$. virescens females, having ORNs and central PNs that responded to $(Z)-9,(E)$-11-tetradecenyl acetate, the female sex pheromone (Ochieng' et al. 1995; Sadek et al. 2002). The behavioral and evolutionary significance for female moth sensitivity to their own odors is yet to be determined.

Few studies have successfully traced ORN projections in female moths. Todd and Baker (1996) successfully stained ORNs responsive to plant volatiles and female sex pheromone in T. ni. Ochieng' et al. (1995) found ORNs sensitive to female sex pheromone which projected to a glomerulus at the base of the antennal nerve in $S$. littoralis. Additionally, Stranden et al. (2003a, b) reported stains of two sensillar types (only a single stain from each study) responding to volatiles from female $H$. assulta using tetramethylrhodamine dextran applied with a tungsten electrode. To our knowledge, the present study represents the first attempt to identify a range of non-female sex pheromonereceptive ORN projections in $H$. virescens.

Much akin to the male MGC, staining of ORNs and digital reconstructions indicate that many of the ORNs specialized for intra-specific odor processing (female sex pheromone components and hairpencil components) have projections near the base of the antennal nerve (See Fig. 11 for a summary of AL projections identified in this study). Only ORNs within sensilla sensitive to both pheromonal odorants Z9-14:Ald or Z9-16:Ald projected beyond the base of the antennal nerve to glomerulus 20 . Additionally, ORNs sensitive to male hairpencil odorants also had axonal arborizations primarily in glomeruli 59 (16:OAc, 18:OAc) and 41 (16:OH), near the base of the antennal nerve.

A large number of ORNs responding to Z9-14:Ald had arborizations associated with the cLFG. Previous work by Galizia et al. (2000) and Skiri et al. (2004) did 
Induced Host Plant Volatiles: Type 16

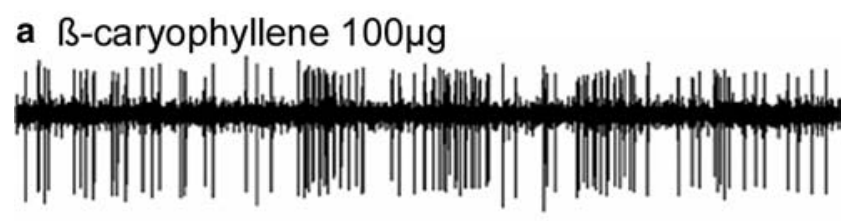

b Hexane

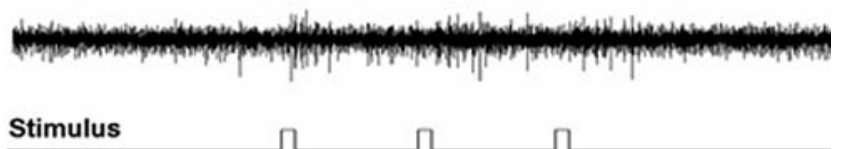

Stimulus
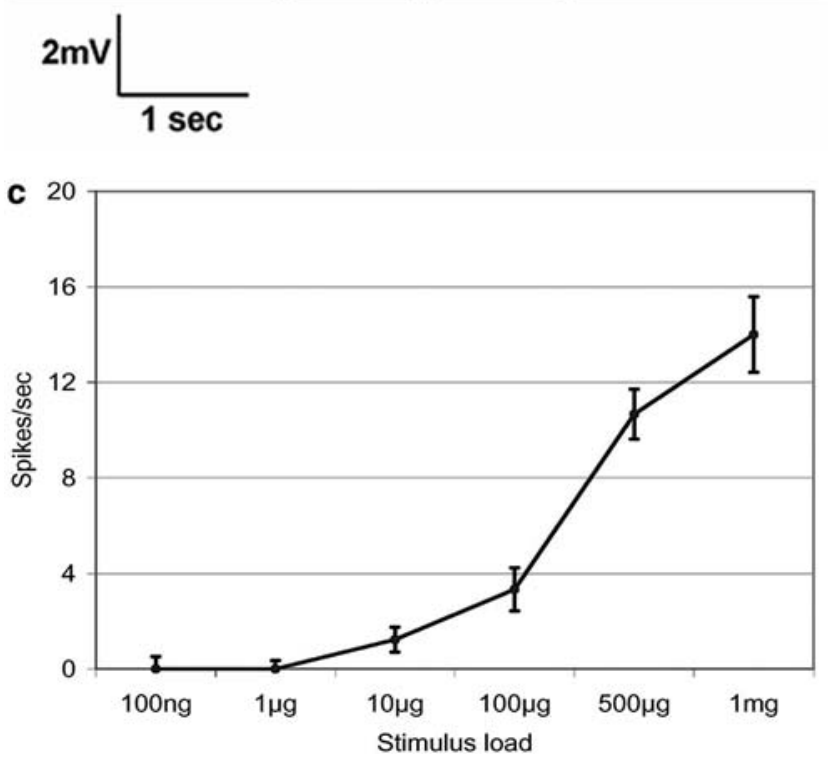

Fig. 10 Type 16 sensillum responses. a b ORN response profile (original spike trains). A female $H$. virescens type 16 sensillum responding to a $\beta$ caryophyllene; b hexane blank. c Dose response curves from ORNs in type 16 sensilla $(N=2)$ stimulated with $\beta$ caryophyllene. Six second total recording time, stimulus delivery $3 \times 100 \mathrm{~ms}$ pulses

not find evidence of calcium-evoked signals in the female $H$. virescens $\mathrm{AL}$ in response to olfactory stimulation using Z9-14:Ald or Z11-16:Ald. One possible reason for this discrepancy is that calcium- imaging studies were generally limited to glomeruli located near the exposed (usually most anterior) portion of the AL. Skiri et al. (2004) recognized that the cLFG was not in focus during their investigation, thereby preventing visualization of this glomerulus' response spectrum. Cobalt-lysine staining permits identification of ORN projections to glomeruli beneath the AL surface. The presence of ORNs sensitive to female $H$. virescens sex pheromone components is supported by a high expression of 'male specific' pheromone binding proteins on the antenna, which have been described previously in female $\mathrm{H}$. virescens (Callahan et al. 2000). Kreiger et al. (2004) also demonstrated the expression of putative pheromone receptor genes on female $H$. virescens antenna, which might correspond to the physiological sensillar types described in the present study.

The identification and localization of glomeruli sensitive to Z9-14:Ald and other pheromone components to the base of the antennal nerve (in a similar area to that of the male MGC) provide a condition for the development of the male MGC through sexual selection, with possible intersexual homology in pheromone-processing glomeruli. Hansson and Christensen (1999) proposed a model for MGC evolution based on inter- and intrasexual selection pressure that drives an increase in the complexity and size of glomeruli. Such a model has been supported by research on female $S$. littoralis, wherein female sex-pheromone sensitive ORNs arborize in an ordinary-sized glomerulus at the base of the antennal nerve, in a location similar to the male MGC (Ochieng' et al. 1995). Todd and Baker (1996) also found evidence of functional partitioning of the female AL based upon responses to odor blends in $T$. ni. ORNs in $T$. $n i$ responding to the major female sex pheromone component projected to an anterior glomerulus, while those excited by floral odors projected to the posterior portion of the AL. The targeting of pheromone-sensitive ORNs to the enlarged cLFG and surrounding glomeruli in $H$. virescens females fits well with this model of MGC development, though the informative benefit to the female moth is yet unclear.

The relative position of glomeruli sensitive to hairpencil and plant volatiles is also of considerable interest. Interglomerular connectivity and local inhibition influence the spatial representation of odors in the $\mathrm{AL}$ (Christensen et al. 2000; Lei et al. 2002). Electrophysiological and behavioral studies have shown that plant volatiles may synergize male responses to pheromones in Helicoverpa zea Boddie and in the tortricid Cydia pomonella L. (Ochieng' et al. 2002; Yang et al. 2004). Accordingly, the context of various odor combinations may result in contrast enhancement or inhibition. The mechanism of such ensemble coding and interglomerular interactions has been investigated previously using female sex pheromone responses in the male MGC (Christensen et al. 2000; Lei et al. 2002).

In addition to the presence of multiple projections to the cLFG of Z9-14:Ald ORNs, type 12 sensilla, housing an ORN sensitive to linalool, showed projections to mLFG and glomerulus 36 . This may be analogous to the organization observed in female $M$. sexta, wherein LFGs are innervated by ORNs sensitive to plant volatiles, and are enantiomer selective for $(+)$ linalool within the 'lateral LFG' (King et al. 2000; Shields and Hildebrand 2001; Reisenman et al. 2004). Further, in our study, EAG responses to linalool were elevated in females relative to males, potentially indicative of female specialization for this odorant, a terpenoid produced by H. virescens host species (De Moraes et al. 1999, 2001). Unfortunately, only two successful stains were made from ORNs in this sensillar type, and it is not possible to differentiate which glomerulus (mLFG or 36) is the target of the linalool-sensitive ORN. As with other 
Fig. 11 Summary of antennal lobe glomerular projections of physiologically characterized ORNs in female $H$. virescens identified from this study, shown in $\mathbf{a}$ anterior, and $\mathbf{b}$ lateral aspect. Glomeruli are numbered according to the $H$. virescens antennal lobe atlas (Berg et al. 2002). Dorsal D; Medial $M$; Anterior, $A$

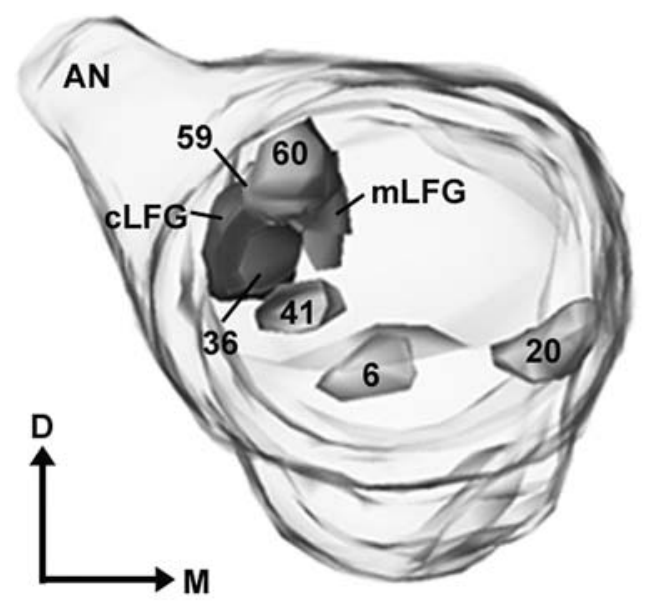

Pheromone:

cLFG: Z9-14:Ald

60:

Z11-16:Ald Z9-14:Ald, Z9-16:Ald, $\mathrm{Z} 11-16: \mathrm{OH}$

20: Z9-14:Ald/Z9-16:Ald

Hairpencil:

59: $16: \mathrm{OAC}$

41: $\quad 16: \mathrm{OH}$

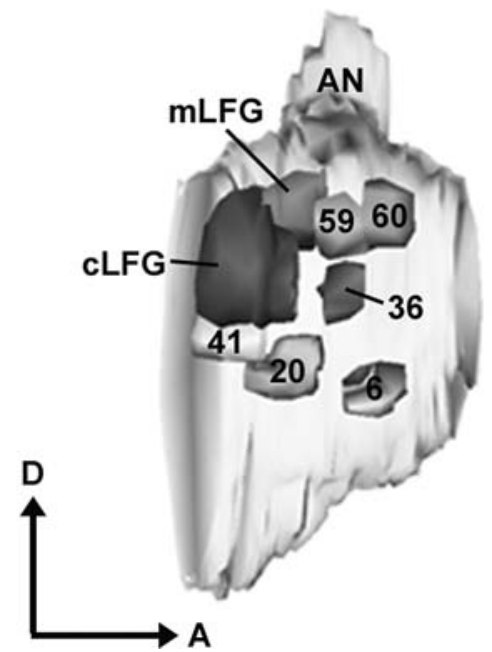

Induced Host Volatiles: mLFG: Linalool

36: Linalool

6: Linalool, B-caryophyllene, Z3-06:OH, Z3-06:OAc sensillar types with projections to multiple glomeruli, intracellular recording and staining of $\mathrm{AL}$ projection neurons will aid in verifying ORN projections observed in the current study.

The responses to linalool were associated with ORNs in several different sensillar types. Notably, ORNs in both type 12 and 13 sensilla responded to linalool (plus three other plant odorants for type 13 sensilla), with projections to different areas of the AL. In the case of pheromone reception in $H$. virescens and other moth species, ORNs responding to a particular odorant will project exclusively to one glomerulus (Hansson et al. 1995; Hansson and Christensen 1999). The presence of different destinations for ORNs within linalool-sensitive sensillar types may be a consequence of a broader tuning of these ORNs, such that some of these ORNs are specialized for an unidentified ligand, but still activate in response to linalool. Thus, various ORNs may have varying sensitivity to odors, producing an 'across-glomerular' code, wherein different glomerular combinations will be activated by specific odors and concentrations. Therefore, for an odorant such as linalool, several glomeruli may be simultaneously activated permitting combinatorial odor coding to discriminate such odorants.
Acknowledgements Special thanks to J. Celestino, K. Iceman and D. Kelly for colony maintenance and to C. Fogarty for valuable comments on the manuscript. We are also grateful to Dr. R. Ra guso and Dr. J. Tumlinson for kindly providing volatile stock solutions. We also thank S.G. Lee and Dr. T.C. Baker for advice with the cobalt lysine staining technique. This research was funded by USDA NRICGP no. 199903541 and NSF IBN 9905683 to NJV.

\section{References}

Almaas TJ, Mustaparta H (1990) Pheromone reception in tobacco budworm moth, Heliothis virescens. J Chem Ecol 16:1331 1347

Almaas TJ, Mustaparta H (1991) Heliothis virescens: Response characteristics of receptor neurons in sensilla trichoidea type 1 and type 2. J Chem Ecol 17:953 972

Almaas TJ, Christensen TA, Mustaparta H (1991) Chemical communication in heliothine moths I. Antennal receptor neu rons encode several features of intra and interspecific odorants in the male corn earworm moth Helicoverpa zea. J Comp Physiol A 169:249 258

Anderson P, Hilker M, Hansson BS, Bombosch S, Klein B, Schildknecht H (1993) Oviposition deterring components in larval frass of Spodoptera littoralis (Boisd.) (Lepidoptera: Noctuidae): a behavioral and electrophysiological evaluation. J Insect Physiol 39:129 137

Anton S, Hansson BS (1994) Central processing of sex pheromone, host odour, and oviposition deterrent information by inter 
neurons in the antennal lobe of female Spodoptera littoralis (Lepidoptera: Noctuidae). J Comp Neurol 350:199 214

Baker TC, Ochieng' SA, Cossé AA, Lee SG, Todd JL, Quero C, Vickers NJ (2004) A comparison of responses from olfactory receptor neurons of Heliothis subflexa and Heliothis virescens to components of their sex pheromone. J Comp Physiol A 190:155 165

Berg BG, Tumlinson JH, Mustaparta H (1995) Chemical com munication in heliothine moths IV. Receptor neuron responses to pheromone compounds and formate analogues in the male tobacco budworm Heliothis virescens. J Comp Physiol A 177:527 534

Berg BG, Almaas TJ, Bjaalie JG, Mustaparta H (1998) The mac roglomerular complex of the antennal lobe in the tobacco budworm moth Heliothis virescens: specified subdivision in four compartments according to information about biologically significant compounds. J Comp Physiol A 183:669 682

Berg BG, Galizia CG, Brandt R, Mustaparta H (2002) Digital atlases of the antennal lobe in two species of tobacco budworm moths, the oriental Helicoverpa assulta (Male) and the American $\mathrm{He}$ liothis virescens (Male and Female). J Comp Neurol 446:123 134

Bernays EA, Chapman RF (1994) Host plant selection by phy tophagous insects. Chapman and Hall, New York

Birch MC (1975) Aphrodisiac pheromones in insects. In: Birch MC (ed) Pheromones. Elsevier, New York, pp 115134

Birch MC, Poppy GM, Baker TC (1990) Scents and eversible scent structures of male moths. Annu Rev Entomol 35:25 58

Bruce TJ, Cork A (2001) Electrophysiological and behavioral re sponses of female Helicoverpa armigera to compounds identi fied in flowers of African marigold, Tagetes erecta. J Chem Ecol 27:1119 1131

Bruce TJ, Cork A, Hall DR, Dunkelblum E (2002) Laboratory and field evaluation of floral odours from African marigold, Tagetes erecta, and sweet pea, Lathyrus odoratus, as kairomones for the cotton bollworm Helicoverpa armigera. Use of pheromones and other semiochemicals in integrated production, IOBC wprs. Bulletin 25:1 9

Callahan FE, Vogt RG, Tucker ML, Dickens JC, Mattoo AK (2000) High level expression of "male specific" pheromone binding proteins (PBPs) in the antennae of female noctuid moths. Ins Biochem Mol Biol 30:507 514

Cardé RT (1984) Chemo orientation in flying insects. In: Bell WJ, Cardé RT (eds) Chemical ecology of insects, 1st edn. Chapman and Hall, London, pp 111124

Cardé RT, Baker TC (1984) Sexual communication with phero mones. In: Bell WJ, Cardé RT (eds) Chemical ecology of in sects, 1st edn. Chapman and Hall, London, pp 355386

Carlsson MA, Galizia CG, Hansson BS (2002) Spatial represen tation of odours in the antennal lobe of the moth Spodoptera littoralis (Lepidoptera: Noctuidae). Chem Senses 27:231 244

Christensen TA (1997) Anatomical and physiological diversity in the central processing of sex pheromonal information in dif ferent moth species. In: Cardé RT, Minks AK (eds) Insect Pheromone Research: New Directions. Chapman and Hall, New York, pp 184193

Christensen TA, Hildebrand JG (1987) Male specific, sex phero mone selective projection neurons in the antennal lobes of the moth Manduca sexta. J Comp Physiol A 160:553 569

Christensen TA, Mustaparta H, Hildebrand JG (1991) Chemical communication in Heliothine moths II. Central processing of intra and interspecific olfactory messages in the male corn earwarm moth Helicoverpa zea. J Comp Physiol A 169:259 274

Christensen TA, Mustaparta H, Hildebrand JG (1995) Chemical communication in Heliothine moths VI. Parallel pathways for information processing in the macroglomerular complex of the male tobacco budworm moth Heliothis virescens. J Comp Physiol A 177:545 557

Christensen TA, Pawlowski VM, Lei H, Hildebrand JG (2000) Multi unit recordings reveal context dependent modulation of synchrony in odor specific neural ensembles. Nat Neurosci 3:927 931
Cork A, Lobos EA (2003) Female sex pheromone components of Helicoverpa gelotopoeon: first heliothine pheromone without (Z) 11 hexadecenal. Ent Exp Appl 107:201 207

Cork A, Boo KS, Dunkelblum E, Hall DR, Jee Rajunga K, Kehat M, Kong Jie E, Park KC, Tepidagarm P, Liu Xun (1992) Fe male sex pheromone of oriental tobacco budworm, Helicoverpa assulta (Guenée) (Lepidoptera: Noctuidae): Identification and field testing. J Chem Ecol 18:403 418

Cossé AA, Todd JL, Baker TC (1998) Neurons discovered in male Helicoverpa zea antennae that correlate with pheromone med iated attraction and interspecific antagonism. J Comp Physiol A $182 \cdot 585594$

Cunningham JP, Moore CJ, Zalucki MP, West SA (2004) Learn ing, odour preference and flower foraging in moths. J Exp Biol 207:87 94

De Moraes CM, Lewis WJ, Paré PW, Tumlinson JH (1999) Her bivore infested plants selectively attract parasitoids. Nature 393:570 574

De Moraes CM, Mescher MC, Tumlinson JH (2001) Caterpillar induced nocturnal plant volatiles repel conspecific females. Nature 410:557 580

den Otter CJ, Schuil HA, Sander van Oosten A (1978) Reception of host plant odours and female sex pheromone in Adoxophyes orana (Lepidoptera: Tortricidae): electrophysiology and mor phology. Entomol Exp Appl 24:370 378

Dickens JC, Jang EB, Light DM, Alford AR (1990) Enhancement of insect pheromone responses by green leaf volatiles. Natur wiss 77:29 31

Dickens JC, Visser JH, van der Pers JNC (1993) Detection and deactivation of pheromone and plant odor components by beet armyworm, Spodoptera exigua (Hübner) (Leipodoptera: Noc tuidae). J Insect Physiol 39:503 516

Finch S (1986) Assessing host plant finding by insects. In: Miller JR, Miller TA (eds) Insect Plant Interactions. Springer, Berlin Heidelberg New York, pp 2363

Fitzpatrick SM, McNeil JN (1988) Male scent in lepidopteran communication: the role of male pheromone in mating behav iour of Pseudaletia unipuncta (Haw.) (Lepidoptera: Noctuidae). Mem Ent Soc Can 146:131 151

Galizia CG, Sachse S, Mustaparta H (2000) Calcium responses to stimulation with pheromones and plant odours in the antennal lobe of the male and female moth Heliothis virescens. J Comp Physiol A 186:1049 1063

Gödde J (1989) Vibrating glass stylets: tools for precise microsur gery on cuticular structures. J Neurosci Methods 29:77 83

Grant AJ, Mayer MS, Mankin RW (1989) Responses from sensilla on the antennae of male Heliothis zea to its major pheromone component and two analogs. J Chem Ecol 15:2625 2634

Hansson BS (1997) Antennal lobe projections of pheromone spe cific olfactory receptor neurons in moths. In: Cardé RT, Minks AK (eds) Insect pheromone research: new directions. Chapman and Hall, New York, pp 164183

Hansson BS, Christensen TA (1999) Functional characteristics of the antennal lobe. In: Hansson BS (ed) Insect Olfaction. Springer, Berlin Heidelberg New York, pp 125163

Hansson BS, Löfquist J, Van der Pers JNC (1989) Comparison of male and female olfactory cell response to pheromone com pounds and plant volatiles in the turnip moth, Agrotis segetum. Physiol Entomol 14:147 155

Hansson BS, Ljungberg H, Hallberg F, Löfstedt C (1992) Func tional specialization of olfactory glomeruli in a moth. Science 256:1313 1315

Hansson BS, Anton S, Almaas TJ (1995) Antennal lobe projection patterns of pheromone detecting receptor neurons in the male Heliothis virescens (Lepidoptera: Noctuidae). J Comp Physiol A 177:535 543

Hartlieb E, Rembold H (1996) Behavioral response of female $\mathrm{He}$ licoverpa (Heliothis) armigera HB. (Lepidoptera: Noctuidae) moths to synthetic pigeonpea (Cajanus cajan L.) kairomone. J Chem Ecol 22:821 837 
Hartlieb EP, Anderson P, Hansson BS (1999) Appetite learning of odours with different behavioural meaning in moths. Physiol Behav 67:671 677

Hildebrand JG (1996) Olfactory control of behavior in moths: central processing of odor information and the functional sig nificance of olfactory glomeruli. J Comp Physiol A 178:5 19

Hildebrand JG, Shepherd GM (1997) Mechanisms of olfactory discrimination: converging evidence for common principles across phyla. Annu Rev Neurosci 20:595 631

Hillier NK, Vickers NJ (2004) The role of heliothine hairpencil compounds in female Heliothis virescens (Lepidoptera: Noc tuidae) behavior and mate acceptance. Chem Senses 29:499 511

Kaissling K E (1974) Sensory transduction in insect olfactory receptors. In: Jaenicke L (ed) Biochemistry of sensory func tions. Springer, Berlin Heidleberg New York, pp 243273

Kennedy JS (1977) Olfactory responses to distant plants and other sources. In: Shorey HH, McKelvey JI Jr (eds) Chemical Control of Insect Behaviour. John Wiley and Sons, New York, pp 6791

Kennedy JS, Marsh D (1974) Pheromone regulated anemotaxis in flying moths. Science 184:999 1001

Kennedy JS, Ludlow AR, Sanders CJ (1980) Guidance system used in moth sex attraction. Nat (Lond) 295:475 477

Kennedy JS, Ludlow AR, Sanders CJ (1981) Guidance of flying male moths by wind borne sex pheromone. Physiol Entomol 6:395 412

King JR, Christensen TA, Hildebrand JG (2000) Response char acteristics of an identified, sexually dimorphic olfactory glo merulus. J Neurosci 20:2391 2399

Klun JA, Plimmer JR, Bierl Leonhardt BA, Sparks AN, Chapman OL (1979) Trace chemicals: the essence of sexual communica tion systems in Heliothis species. Science 204:1328 1330

Klun JA, Plimmer JR, Bierl Leonhardt BA, Sparks AN, Primiani M, Chapman OL, Lee GH, Lepone G (1980a) Sex pheromone chemistry of female corn earworm moth, Heliothis zea. J Chem Ecol 6:165 175

Klun JA, Plimmer JR, Bierl Leonhardt BA, Sparks AN, Primiani M, Chapman OL, Lepone G, Lee GH (1980b) Sex pheromone chemistry of female tobacco budworm moth, Heliothis vires cens. J Chem Ecol 6:177 183

Klun JA, Leonhardt BA, Lopez JD Jr, Lachance LE (1982) Female Heliothis subflexa (Lepidoptera: Noctuidae) sex pheromone: chemistry and congeneric comparisons. Environ Entomol 11:1084 1090

Koh YH, Park KC, Boo KS (1995) Antennal sensilla in adult Helicoverpa assulta (Lepidoptera: Noctuidae): morphology, distribution and ultrastructure. Ann Entomol Soc Am 88:519 530

Krieger J, Grosse Wilde E, Gohl T, Dewer YME, Raming K, Breer $\mathrm{H}$ (2004) Genes encoding candidate pheromone receptors in a moth (Heliothis virescens). Proc Natl Acad Sci, USA 101:11845 11850

Landolt PJ, Phillips TW (1997) Host plant influences on sex pheromone behavior of phytophagous insects. Annu Rev Entomol 42:371 391

Lei H, Christensen TA, Hildebrand JG (2002) Local inhibition modulates odor evoked synchronization of glomerulus specific output neurons. Nat Neurosci 5:557 565

Ljungberg H, Anderson P, Hansson BS (1993) Physiology and morphology of pheromone sensitive sensilla on the antennae of male and female Spodoptera littoralis. J Insect Physiol 39:253 260

Masante Roca I, Gadenne C, Anton S (2002) Plant odour pro cessing in the antennal lobe of male and female grapevine moths, Lobesia botrana (Lepidoptera: Tortricidae). J Insect Phys 48:1111 1121

Meijerink J, Carlsson MA, Hansson BS (2003) Spatial represen tation of odorant structure in the moth antennal lobe: a study of structure response relationships at low doses. J Comp Neurol 467:11 21

Mitchell ER, Tingle FC, Heath RR (1991) Flight activity of $\mathrm{He}$ liothis virescens (F.) females (Lepidoptera: Noctuidae) with reference to host plant volatiles. J Chem Ecol 17:259 266
Murlis J (1997) Odor plumes and the signal they provide. In: Cardé RT, Minks AK (eds) Insect pheromone research: new direc tions. Chapman and Hall, New York, pp 221231

Murlis J, Elkinton JS, Cardé RT (1992) Odour plumes and how insects use them. Annu Rev Entomol 37:505 532

Mustaparta H (2002) Encoding of plant information in insects: peripheral and central mechanisms. Entomol Exp Appl 104:1 13

Nagai T (1983) On the relationship between the electroantenno gram and simultaneously recorded single sensillum response of the European corn borer, Ostrina nubalis. Arch Insect Biochem Physiol 1:85 91

Ochieng' SA, Anderson P, Hansson BS (1995) Antennal lobe projection patterns of olfactory receptor neurons involved in sex pheromone detection by Spodoptera littoralis (Lepidoptera: Noctuidae). Tissue Cell 27:221 232

Ochieng' SA, Park KC, Baker TC (2002) Host plant volatiles synergize responses of sex pheromone specific olfactory recep tor neurons in male Helicoverpa zea. J Comp Physiol 188:325 333

Ochieng' SA, Poole K, Linn CE, Vickers NJ, Roelofs WL, Baker TC (2003) Unusual pheromone receptor neuron responses in heliothine moth antennae derived from inter species imaginal disc transplantation. J Comp Physiol A 189:19 28

Palaniswamy P, Seabrook WD (1978) Behavioral responses of the female eastern spruce budworm Choristoneura fumiferana (Lepidoptera, Tortricidae) to the sex pheromone of her own species. J Chem Ecol 4:649 655

Quero C, Baker TC (1999) Antagonistic effect of $(Z) 11$ hexa decen $1 \mathrm{ol}$ on the pheromone mediated flight of Helicoverpa zea (Boddie) (Lepidoptera: Noctuidae). J Insect Behav 12:701 709

Quero C, Fadamiro HY, Baker TC (2001) Responses of male Helicoverpa zea to single pulses of sex pheromone and behavioural antagonist. Physiol Entomol 26:106 115

Raguso RA, Willis MA (2002) Synergy between visual and olfac tory cues in nectar feeding by naïve hawkmoths, Manduca sexta. Anim Behav 64:685 695

Reisenman CE, Christensen TA, Francke W, Hildebrand JG (2004) Enantioselectivity of projection neurons innervating identified olfactory glomeruli. J Neurosci 24:2602 2611

Roelofs WL (1979) Electroantennograms. Chemtech 9:222 227

Røstelien T, Borg Karlson A K, Fäldt J, Jacobson U, Mustaparta H (2000a) The plant sesquiterpene germacrene D specifically activates a major type of antennal receptor neuron of the to bacco budworm moth Heliothis virescens. Chem Senses 25:141 148

Røstelien T, Borg Karlson A K, Fäldt J, Jacobson U, Mustaparta $\mathrm{H}(2000 \mathrm{~b})$ Selective receptor responses to $E \beta$ ocimene, $\beta$ myrcene, $E, E \alpha$ farnesene and homo farnesene in the moth Heliothis virescens, identified by gas chromatography linked to electrophyiosology. J Comp Physiol A 186:833 847

Røstelien T, Stranden M, Borg Karlson A K, Mustaparta H (2005) Olfactory receptor neurons in two heliothine mot species responding selectively to aliphatic green leaf volatiles, aromatic compounds, monoterpenes and sesquiterpenes of plant origin. Chem Senses 30:443 461

Sadek MM, Hansson BS, Rospars JP, Anton S (2002) Glomerular representation of plant volatiles and sex pheromones compo nents in the antennal lobe of the female Spodoptera littoralis. J Exp Biol 205:1363 1376

Schneider D (1962) Electrophysiological investigation on the olfactory specificity of sexual attracting substances in different species of moths. J Insect Physiol 8:15 30

Seabrook WD, Linn CE, Dyer LJ, Shorey HH (1987) Comparison of electroantennograms from female and male cabbage looper moths (Trichoplusia ni) of different ages and for various pher omone concentrations. J Chem Ecol 13:1443 1453

Shields VDC, Hildebrand JG (2001) Responses of a population of antennal olfactory receptor cells in the female moth Manduca sexta to plant associated volatile organic compounds. J Comp Physiol A 186:1135 1151 
Shorey HH, Hale RL (1956) Mass rearing of the larvae of nine noctuid species on a simple artificial medium. J Econ Entomol 58:522 524

Skiri HT, Galizia CG, Mustaparta H (2004) Representation of primary plant odorants in the antennal lobe of the moth $\mathrm{He}$ liothis virescens using calcium imaging. Chem Senses 29:253 267

StatSoft, Inc. (1999) STATISTICA for Windows [Computer pro gram manual]. StatSoft, Inc., Tulsa. http://www.statsoft.com

Stranden M, Liblikas I, König WA, Almaas TJ, Borg Karlson A K, Mustaparta H (2003a) ( ) Germacrene D receptor neurones in three species of heliothine moths: structure activity rela tionships. J Comp Physiol A 189:563 577

Stranden M, Røstlien T, Liblikas I, Almaas TJ, Borg Karlson A K, Mustaparta H (2003b) Receptor neurons in three heliothine moths responding to floral and inducible plant volatiles. Chemoecology 13:143 154

Teal PES, Tumlinson JH (1989) Isolation, identification and bio synthesis of compounds produced by male hairpencil glands of Heliothis virescens (F.) (Lepidoptera: Lepidoptera). J Chem Ecol 15:413 427

Teal PEA, Heath RR, Tumlinson JH, McLaughlin JR (1981) Identification of a sex pheromone of Heliothis subflexa (GN.) (Lepidoptera: Noctuidae) and field trapping studies using dif ferent blends. J Chem Ecol 7:1011 1022

Teal PEA, Tumlinson JH, McLaughlin JR, Heath R, Rush RA (1984) (Z) 11 Hexadecen 1 ol: a behavioral modifying chemical present in the pheromone gland of female Heliothis zea (Lepi doptera: Noctuidae). Can Entomol 116:777 779

Teal PEA, Tumlinson JH, Heath RR (1986) Chemical and behavioral analyses of volatile sex pheromone components re leased by calling Heliothis virescens $(\mathrm{F}$.) females (Lepidoptera: Noctuidae). J Chem Ecol 12:107 125

Timm F (1958) Zur Histochemie der Schwermetalle. Das sulfide Silber Verfahren. Dtsch Z Gesamte Gerichtl Med 46:706 711

Tingle FC, Mitchell ER (1992) Attraction of Heliothis virescens (F.)(Lepidoptera: Noctuidae) to volatiles from extracts of cot ton flowers. J Chem Ecol 18:907 914

Tingle FC, Heath RR, Mitchell ER (1989) Flight response of $H e$ liothis subflexa $(\mathrm{Gn}$.$) females (Lepidoptera: Noctuidae) to an$ attractant from groundcherry, Physalis angulata L. J Chem Ecol 15:221 231
Todd JL, Baker TC (1993) Response of single antennal neurons of female cabbage loopers to behaviorally active attractants. $\mathrm{Na}$ turwissenschaften 80:183 186

Todd JL, Baker TC (1996) Antennal lobe partitioning of behav iorally active odors in female cabbage looper moths. Natur wissenschaften 83:324 326

Todd JL, Anton S, Hansson BS, Baker TC (1995) Functional organization of the macroglomerular complex related to behaviourally expressed olfactory redundancy in male cabbage looper moths. Physiol Entomol 20:349 361

Tumlinson JH, Hendricks PE, Mitchell ER, Doolittle RE, Brennan MM (1975) Isolation, identification and synthesis of the sex pheromone of the tobacco budworm. J Chem Ecol 1:203 214

Van der Pers J, den Otter CJ (1978) Single cell responses from olfactory receptors of small ermine moths to sex attractants. J Insect Physiol 24:337 343

Vetter RS, Baker TC (1983) Behavioral responses of male Heliothis virescens in a sustained flight tunnel to combinations of seven compounds identified from female sex pheromone glands. J Chem Ecol 9:747 759

Vickers NJ (2002) Defining a synthetic pheromone blend attractive to male Heliothis subflexa under wind tunnel conditions. J Chem Ecol 28:1255 1267

Vickers NJ, Baker TC (1992) Male Heliothis virescens maintain upwind flight in response to experimentally pulsed filaments of their sex pheromone (Lepidoptera: Noctuidae). J Insect Behav 5:669 687

Vickers NJ, Christensen TA (2003) Functional divergence of spa tially conserved glomeruli in two related moth species. Chem Senses 28:325 338

Vickers NJ, Christensen TA, Hildebrand JG (1998) Combinatorial odor discrimination in the brain: attractive and antagonist odor blends are represented in distinct combinations of uniquely identifiable glomeruli. J Comp Neurol 400:35 36

Visser JH (1979) Electroantennogram responses of the Colorado beetle, Leptinotarsa decemlineata, to plant volatiles. Ent Exp Appl 25:86 97

Visser JH (1986) Host odor perception in phytophagous insects. Ann Rev Entomol 31:121 144

Yang Z, Bengtsson M, Witzgall P (2004) Host plant volatiles synergize response to sex pheromone in codling moth, Cydia pommonella. J Chem Ecol 30:619 629 